\title{
ALUMINIUM SHEAR-LINKS FOR ENHANCED SEISMIC RESISTANCE
}

\author{
DURGESH C. RAI ${ }^{1 * \dagger}$ AND BENJAMIN J. WALLACE ${ }^{2 \ddagger}$ \\ ${ }^{1}$ Department of Civil and Environmental Engineering, University of Michigan, Ann Arbor, MI 48109, U.S.A. \\ ${ }^{2}$ Department of Civil Engineering and Environmental Science, University of Oklahoma, Norman, OK 73069, U.S.A.
}

\begin{abstract}
SUMMARY
An aluminium beam shear-link is developed for earthquake-resistant structures. The aluminium beam is designed to yield in shear mode to limit the maximum lateral force which is transmitted to primary structural members and to provide significant energy dissipation potential. Aluminium was chosen because of its low yield strength, which enables the use of thicker webs, reducing the problems of web buckling. Cyclic load tests on medium scale (1:4) models were conducted to study the hysteretic behaviour and energy dissipation potential of shear-links made of two alloys of aluminium (3003-O and 6061-O). The links were also tested at faster rates (cycling frequencies of 5, 10 and $17 \mathrm{~Hz}$ ) to determine the effect of strain rate. The links exhibited very ductile shear yielding and excellent energy dissipation capacity. Unpinched and full hysteresis loops were observed until 10 per cent shear strain, and a relatively small influence of strain rates was observed on the link's performance. Simple design equations are developed to proportion these shear-links, using data from the cyclic load tests. In chevron-type braced systems, the shear-link is sandwiched between the tops of diagonal braces and a girder from the floor above, resulting in yielding at a lateral force less than that required to buckle the compression brace. A Shear-Link Braced Frame (SLBF) system was designed and its seismic performance was compared to that of an Ordinary Concentric Braced Frame (OCBF) with chevron braces. The SLBF system demonstrated more uniform distribution of storey drifts, reduced base shear, and a larger energy dissipation capacity per unit drift. (C) 1998 John Wiley \& Sons, Ltd.
\end{abstract}

KEY WORDS: earthquake-resistant; shear-link; bracing; aluminium

\section{INTRODUCTION}

A current area of emphasis in structural engineering is the search for better ways to improve the seismic resistance of structures. This paper discusses a study of aluminium shear-links used with various structural frames for lateral resistance. I-shaped shear-links of low yielding ductile alloys of aluminium function primarily as a metallic yielding device ('fuse') limiting the maximum lateral force that can be transmitted to primary structural members and providing significant energy dissipation potential. These aluminium links can also be viewed as a damping device which dissipates earthquake induced energy through inelastic deformations (metallic hysteresis), thus minimizing (or eliminating) the energy dissipation demand on the primary structural members. These properties make the aluminium shear-links attractive for both new buildings and improvements to existing structures.

One application of the aluminium shear-link is to modify the behaviour of chevron-type Ordinary Concentric Braced Frames (OCBFs). An I-shaped aluminium beam is sandwiched between the tops of the

\footnotetext{
* Correspondence to: Durgesh C. Rai, Department of Earthquake Engineering, University of Roorkee, Roorkee 247 667, India

$\dagger$ Research Fellow

‡Associate Professor
}

Contract grant sponsor: University of Oklahoma Research Council 
diagonal braces and a beam from the floor above, as shown in Figure 1(a). The aluminium beam is designed to yield in shear mode at a lateral force less than that required to buckle the compression brace, eliminating the severe loss of storey strength and stiffness due to compression brace buckling. Figure 1(b) shows the collapse mechanism for a typical one-storey Shear-Link Braced Frame (SLBF). An obvious advantage of this bracing system is that the floor beam continues to carry gravity loads even after link collapse.

The objective of the paper is to describe the inelastic cyclic behaviour of the shear-link and its role as a seismic energy dissipator in a bracing frame structural system. The experimental part includes the effects of different alloys of aluminium, the arrangement of transverse stiffeners, and strain rates on the hysteretic behaviour and energy dissipation capacity of shear-links. ${ }^{1}$ Various design and hysteretic characteristics of the shear-links are derived from the in-plane shear testing of medium scaled (1:4) models of the link subassemblages. In the Part II of the paper, a design methodology for a SLBF system is developed, and a numerical assessment of its seismic performance is compared to an OCBF system. A chevron-type OCBF

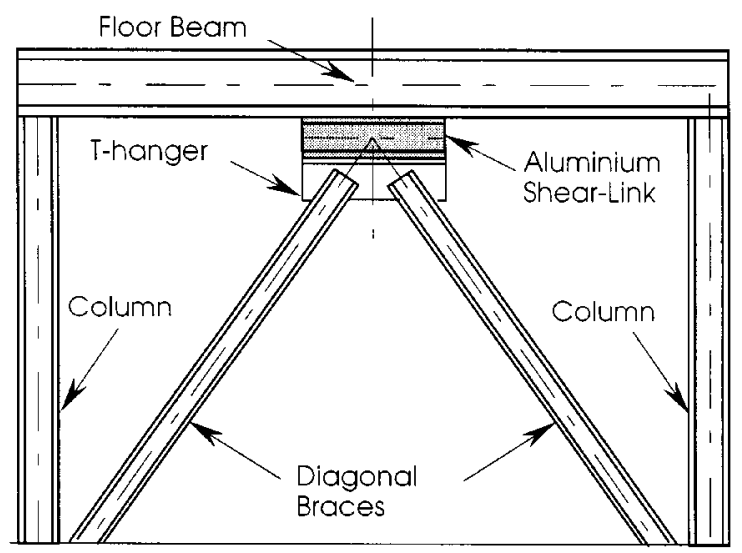

(a)

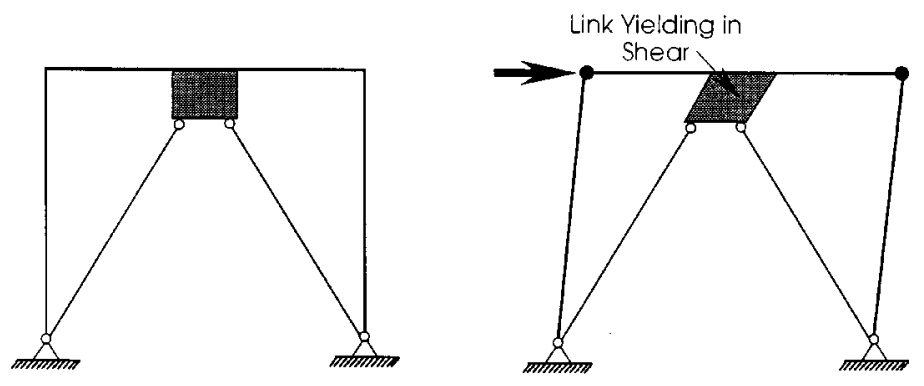

(b)

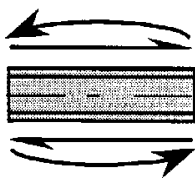

(c)

Figure 1. (a) Schematic diagram and (b) typical collapse mechanism of the proposed bracing system and (c) the isolated shear-link from the bracing system 
for an office building is designed in accordance with Uniform Building Code $1994^{2}$ and, for the same building, a SLBF is designed with suitable assumptions. Their performance under a static 'pushover' and simulated earthquake-type loadings are then investigated, utilizing the SNAP-2D computer program ${ }^{3}$ with a suitable hysteretic model for shear-links.

\section{ALUMINIUM SHEAR-LINKS}

Aluminium was chosen for the shear-link because of its low yield strength, enabling the use of thicker webs, which reduces the problems of web buckling. Moreover, soft alloys of aluminium last through many large plastic deformation cycles before tearing. The shear yielding of the web maximizes the material yielding without excessive localized strains as opposed to gradual plastification of the section in bending. In shear mode, they can achieve greater ductilities and dissipate more energy. Furthermore, strain hardening in shear mode increases the ultimate shear capacity well above the yield value. The significant amount of strain hardening of aluminium alloys will enable the first link to yield in a multistorey building and then resist more lateral load, causing additional deformations to be absorbed by links in other storeys. Thus, strain hardening enables all of the links in a structure to participate in dissipating seismic energy and avoids the creation of an undesirable 'soft storey' - a problem of concentrated storey deformation.

Other devices have been proposed by other investigators which aim at modifying the seismic response of structural systems by dissipating seismic energy through utilization of friction, metallic hysteresis and viscous and viscoelastic materials. A state-of-the-art review of these energy dissipation devices is presented by Hanson et al. ${ }^{4}$ ADAS element is one such device using X-shaped steel plates to maximize the material yielding in bending, which is very similar to the proposed aluminium shear-link in the application, and which relies on metal yielding and hysteresis for dissipating energy. ${ }^{5}$

\section{PART I: HYSTERETIC BEHAVIOR OF ALUMINIUM SHEAR-LINKS}

\section{EXPERIMENTAL PROGRAM}

\section{Modeling process}

The shear-link was isolated from the proposed bracing configuration as shown in Figure 1(c). The underlying assumptions in the modeling process are: (1) Inelastic actions are concentrated only in the shear-link, when the structure is loaded, since the shear-link is made of soft alloys of aluminium and is proportioned to yield at lower storey shear forces and drifts than other elements of the structure. (2) The shear-link carries zero vertical forces, which is justifiable considering the chevron pattern of diagonal braces, where the vertical components of the brace forces are balanced and the beams are assumed to be proportioned to carry gravity loads to the columns. However, if transverse compression is included in the shear-link loading to support the centre of beam, additional stiffeners may be added to resist this force without compromising the shear-link's performance.

\section{Testing system}

Based on the aforementioned modelling assumptions, a testing system was designed as shown in Figure 2. A medium scale of 1:4 was chosen as the best compromise between specimen manufacturing ease and the available test equipment. This scale resulted in specimens approximately $51.6 \mathrm{~mm}$ deep and $152.4 \mathrm{~mm}$ long. The isolated link, as shown in Figure 1(c), was turned through $90^{\circ}$ and then tested in this vertical position. The load was transferred from the actuator to the specimen through a pair of rigid L-shaped fixtures which moved up and down with the actuator. The specimen was securely bolted to in-plane vertical legs of the top and bottom fixture. The second vertical leg of the top fixture was laterally braced to the vertical leg of the bottom fixture to ensure the stability of the system and to prevent out-of-plane bending and twisting of the test specimen. 


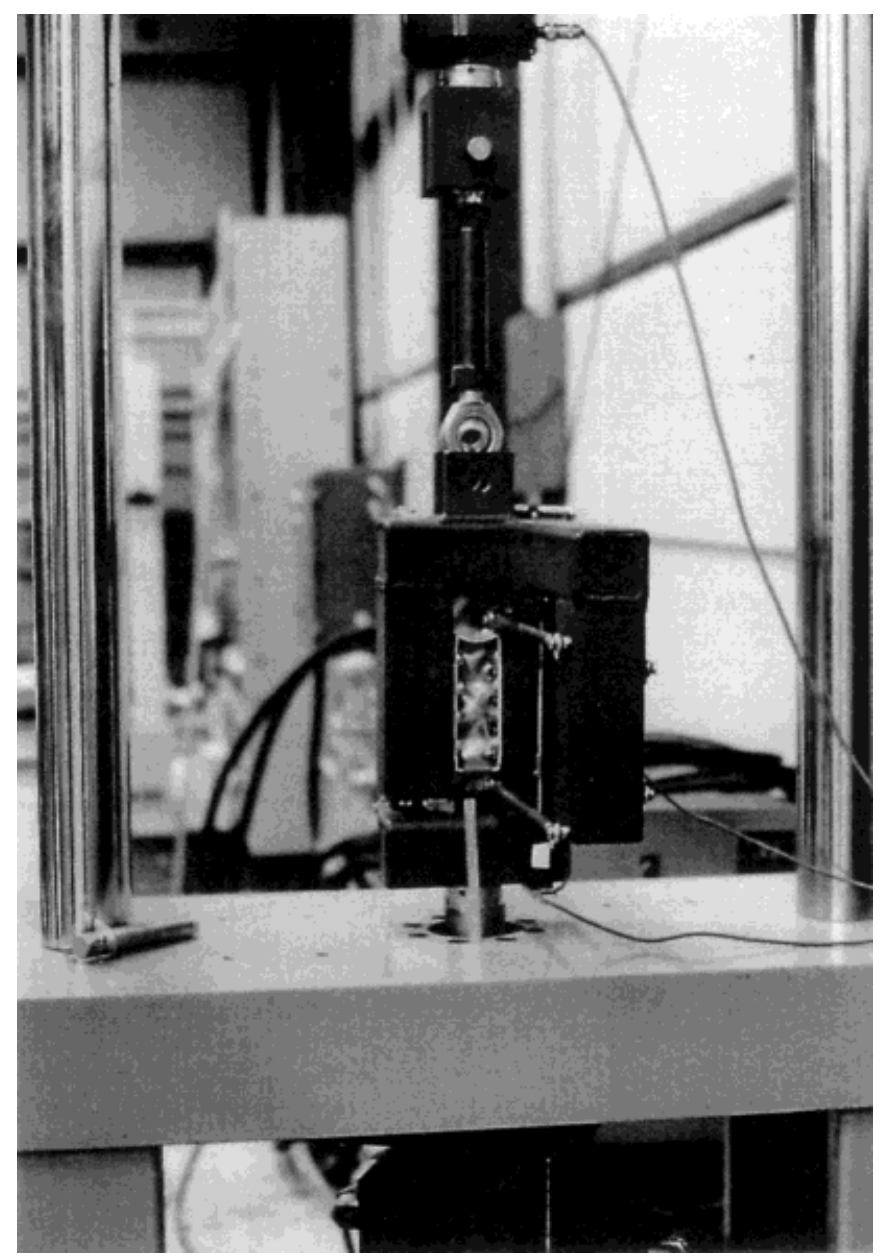

Figure 2. Details of the test fixture

\section{Test specimens}

Specimens of two different section dimensions are used in the test, as given in Table I, which differ only in the dimensions of their flange widths. The flange width of specimens used in the strain rate studies was increased to $63.5 \mathrm{~mm}$ so that more fasteners could be provided to avoid the bolt slippage observed with specimens used for material evaluation. These two section types behaved nearly alike since, in this application, flanges have a negligibly small effect on the overall link behaviour, which is dominated by shear stresses and deformations in the web.

Two different alloys of aluminium, 3003 and 6061, of temper $\mathrm{O}$ (fully soft and annealed condition) were used in the web of specimens to evaluate their relative performance. The flanges of all specimens were made of 6061 alloy, as the behaviour of the specimen is little influenced by the material properties of the flanges. Alloy 3003 uses manganese as its main alloying element to attain a moderate increase in strength over pure aluminium without seriously affecting its excellent workability (ductility). Alloy 6061 uses manganese and silicon for a combination of high strength, corrosion resistance, and weldability, and it is also widely used in structural applications. Reference material properties of alloys, listed in Table II, were obtained from uniaxial tension coupon tests. 
Table I. Specimen details

\begin{tabular}{|c|c|c|c|c|c|}
\hline $\begin{array}{l}\text { Test feature } \\
\text { (1) }\end{array}$ & $\begin{array}{c}\text { Specimen } \\
\text { number } \\
\text { (2) }\end{array}$ & $\begin{array}{c}\text { Web } \\
\text { material } \\
\text { (3) }\end{array}$ & $\begin{array}{l}\text { Geometric } \\
\text { dimensions* } \\
\text { (4) (mm) }\end{array}$ & $\begin{array}{l}\text { Stiffener details } \\
\text { (5) }\end{array}$ & $\begin{array}{l}\text { Cycling } \\
\text { frequency } \\
\text { (6) }\end{array}$ \\
\hline $\begin{array}{l}\text { Material } \\
\text { selection }\end{array}$ & $\begin{array}{l}1 \\
2 \\
3 \\
5^{\dagger} \\
6\end{array}$ & $\begin{array}{l}3003-\mathrm{O} \\
3003-\mathrm{O} \\
3003-\mathrm{O} \\
6061-\mathrm{O} \\
6061-\mathrm{O}\end{array}$ & $\begin{aligned} d_{\mathrm{w}} & =45 \cdot 2 \\
t_{\mathrm{w}} & =1 \cdot 6 \\
b_{\mathrm{f}} & =31 \cdot 8 \\
t_{\mathrm{f}} & =3 \cdot 2 \\
l & =152 \cdot 4\end{aligned}$ & $\begin{array}{c}\text { No Stiffener } \\
\text { End stiffener only } \\
\text { End + intermediate stiffener } \\
\text { End stiffener only } \\
\text { End + intermediate stiffener }\end{array}$ & $\begin{array}{l}\text { Pseudo-static } \\
\text { Pseudo-static } \\
\text { Pseudo-static } \\
\text { Pseudo-static } \\
\text { Pseudo-static }\end{array}$ \\
\hline $\begin{array}{l}\text { Strain rate } \\
\text { effects }\end{array}$ & $\begin{array}{r}7 \\
8 \\
9 \\
10 \\
11 \\
12 \\
13 \\
14\end{array}$ & $\begin{array}{l}3003-\mathrm{O} \\
3003-\mathrm{O} \\
3003-\mathrm{O} \\
3003-\mathrm{O} \\
3003-\mathrm{O} \\
3003-\mathrm{O} \\
3003-\mathrm{O} \\
3003-\mathrm{O}\end{array}$ & $\begin{aligned} d_{\mathrm{w}} & =45 \cdot 2 \\
t_{\mathrm{w}} & =1 \cdot 6 \\
b_{\mathrm{f}} & =63 \cdot 5 \\
& \\
t_{\mathrm{f}} & =3 \cdot 2 \\
l & =152 \cdot 4\end{aligned}$ & End stiffener only & $\begin{array}{c}5 \mathrm{~Hz} \\
5 \mathrm{~Hz} \\
5 \mathrm{~Hz} \\
10 \mathrm{~Hz} \\
10 \mathrm{~Hz} \\
17 \mathrm{~Hz} \\
0 \cdot 01 \mathrm{~Hz} \\
17 \mathrm{~Hz}\end{array}$ \\
\hline
\end{tabular}

$* d_{\mathrm{w}}$ and $t_{\mathrm{w}}$ are clear depth and thickness of the web; $b_{\mathrm{f}}$ and $t_{\mathrm{f}}$ are width and thickness of the flange of the shear-link of length $l$

${ }^{\dagger}$ Specimen 4 broke prematurely due to an equipment malfunction

Table II. Properties of aluminium alloys used in the investigation

\begin{tabular}{ccccc}
\hline $\begin{array}{c}\text { Aluminium } \\
\text { alloys } \\
(1)\end{array}$ & $\begin{array}{c}0 \cdot 2 \% \text { yield } \\
\text { stress } \\
(\mathrm{MPa}) \\
(2)\end{array}$ & $\begin{array}{c}\text { Tensile strength } \\
(\mathrm{MPa}) \\
(3)\end{array}$ & $\begin{array}{c}\text { Ultimate strain } \\
(\mathrm{mm} / \mathrm{mm}) \\
(4)\end{array}$ & $\begin{array}{c}\text { Young's } \\
\text { modulus } \\
(\mathrm{GPa}) \\
(5)\end{array}$ \\
\hline $3003-\mathrm{O}$ & $35 \cdot 2$ & $109 \cdot 2$ & $0 \cdot 2396$ & 62 \\
$6061-\mathrm{O}$ & $52 \cdot 8$ & $126 \cdot 3$ & $0 \cdot 2961$ & 69 \\
\hline
\end{tabular}

Two different arrangements of transverse stiffeners were employed. In the first, stiffeners were provided at the ends of the link, while in the other, two intermediate stiffeners were also added. However, the first specimen was tested with no web stiffening. The purpose of the stiffeners was to delay the initiation of plastic web buckling and to improve the postbuckling behaviour of the links. The end stiffeners were grove-welded to both flanges as well as to the web, whereas the intermediate stiffeners were welded to flanges only because of expected difficulty in making the fillet welds to the web without damaging the web at this scale. The typical geometric details of a test specimen is illustrated in Figure 3 and a summary of all specimens tested is given in Table I.

The Wallace and Rajendran ${ }^{6}$ method of manufacturing small-scale wide-flanged I-section ${ }^{7}$ was used. This method consisted of making an I-section from five strips (two separate strips for each of the flanges and one strip for the web) and TIG welding the flange and web strips from the outside of the flange. The heat input in welded regions removes the effect of the thermal treatment provided to the aluminium alloy to improve its mechanical properties, resulting in a distribution of strength varying along the cross-section of the profile, with the minimum at the weld equal to the elastic limit of the annealed material. The entire specimen was annealed and, hence, relieved from residual stresses before the experiment, by heating to and holding at a temperature of $775^{\circ} \mathrm{F}\left(413^{\circ} \mathrm{C}\right)$ for $2 \mathrm{~h}$ before being allowed to cool gradually at a rate of $50^{\circ} \mathrm{F}\left(28^{\circ} \mathrm{C}\right)$ per hour in the heat treating oven. 

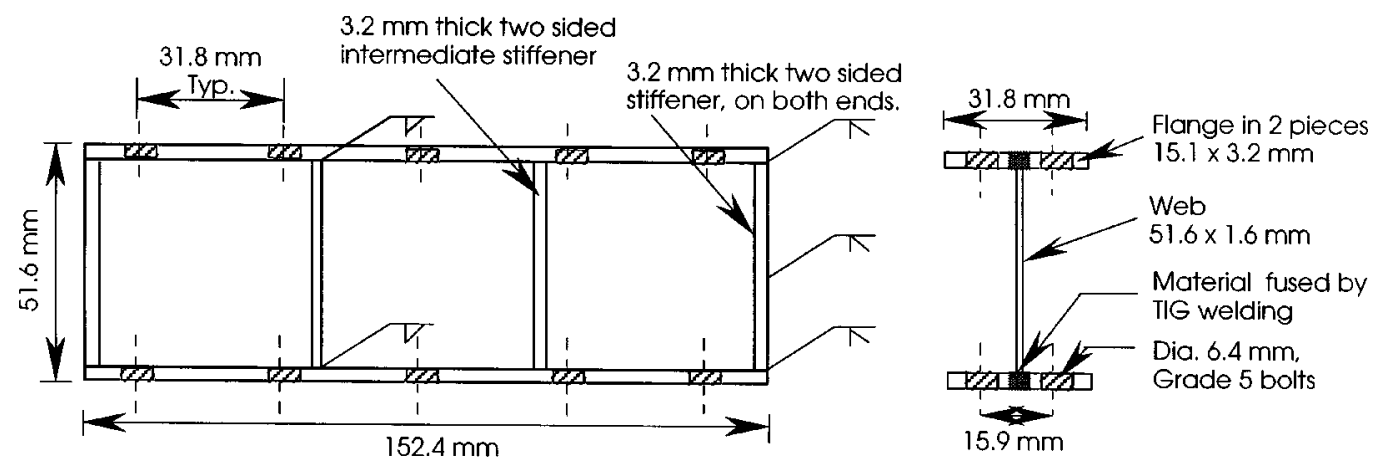

Figure 3. Geometric details of a typical test specimen

\section{Instrumentation}

A $55.6 \mathrm{kN}$ universal load cell was included in the test setup to measure the force in the specimen, as shown in Figure 2. With the forces known, the average shear stress resultant in the web of the specimen was determined by dividing the shear load by web area (web thickness times link length). A pair of displacement transducers (LVDTs and linear potentiometers) were mounted on the vertical limbs of the fixture on either face in diagonally opposite directions. The average reading of the two instruments provided the measure of the shearing deformation in the plane of the specimen web. This shear deformation is divided by the clear distance between flanges to obtain the reported shear strain.

\section{Loading history}

Specimens were subjected to sinusoidal input waves during both the stress and strain controlled regimes of the testing program. For quasi-static tests, a typical loading program began with three cycles at $8.3 \mathrm{MPa}$ of web shear stress, then three cycles at $20.7 \mathrm{MPa}$, which was near the expected yield stress of the web material. At this stage, the experiment was switched to the strain-controlled mode and groups of three cycles were performed at strain levels of 0.002, 0.005, 0.02, 0.05, 0.1, 0.2 ( $\mathrm{mm} / \mathrm{mm})$, etc., strains until specimen failure. Each cycle consisted of two displacement excursions from the state of zero load - one in the downward direction (i.e. 'tension' for the actuator) and the other one in the upward direction (i.e. a 'compression' for the actuator).

To understand the effect of different strain rates on the shear-link behaviour, specimens were tested at three cycling frequencies-5, 10 and $17 \mathrm{~Hz}$. One specimen was tested at a frequency of $0.01 \mathrm{~Hz}$ and can be considered representative of a pseudo-static test, which served as the basis for comparison. The loading program was comprised of 3 cycles each of $0 \cdot 005,0 \cdot 02,0 \cdot 05,0 \cdot 1$ and $0 \cdot 2(\mathrm{~mm} / \mathrm{mm})$ strain.

\section{OBSERVED HYSTERETIC BEHAVIOUR}

\section{Pseudo-static cyclic tests}

A typical shear stress-strain hysteretic behaviour of a shear-link (with only end stiffeners, specimen 2 ) is shown in Figure 4. The first yielding of the web was observed at the first cycle of $20.9 \mathrm{MPa}$, at a strain of 0.002 . The onset of web buckling was delayed until the second cycle of 0.1 strain. The web continued to strain-harden with increasing strains until the peak stress of $55.0 \mathrm{MPa}$, which is nearly 2.6 times the initial yield stress. Stable hysteresis loops are observed until the $0 \cdot 1$ strain cycles. During the next cycles of $0 \cdot 2$ strain, rapid degradation of strength was observed, accentuating with each additional cycle. Despite the visibly distressed end stiffeners at this stage, the specimen retained good capacity. Shortly after each load reversals (regions in the dashed circles in Figure 4), some loss of loading stiffness was observed due to bolt slippage at 


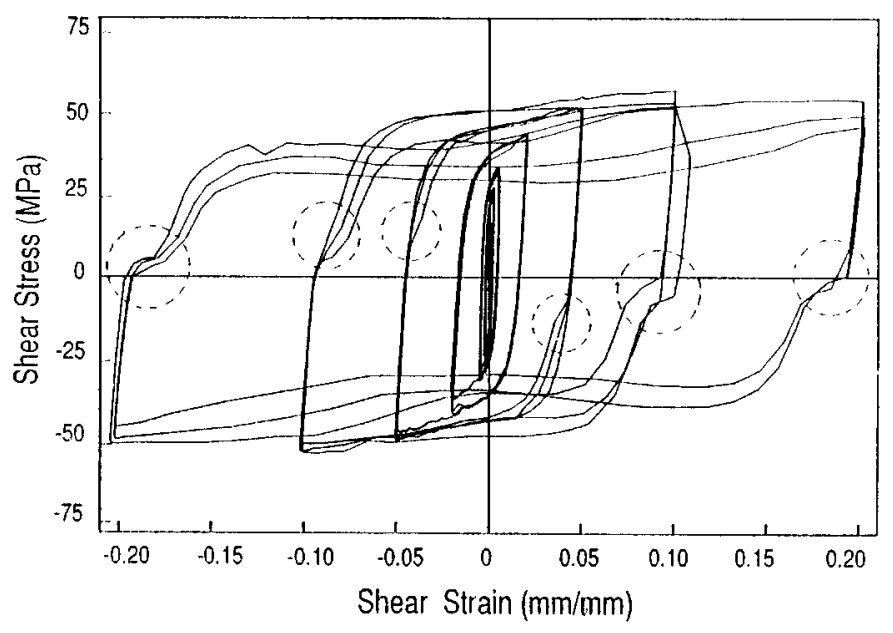

Figure 4. Typical hysteretic behaviour of a shear-link (Specimen 2)

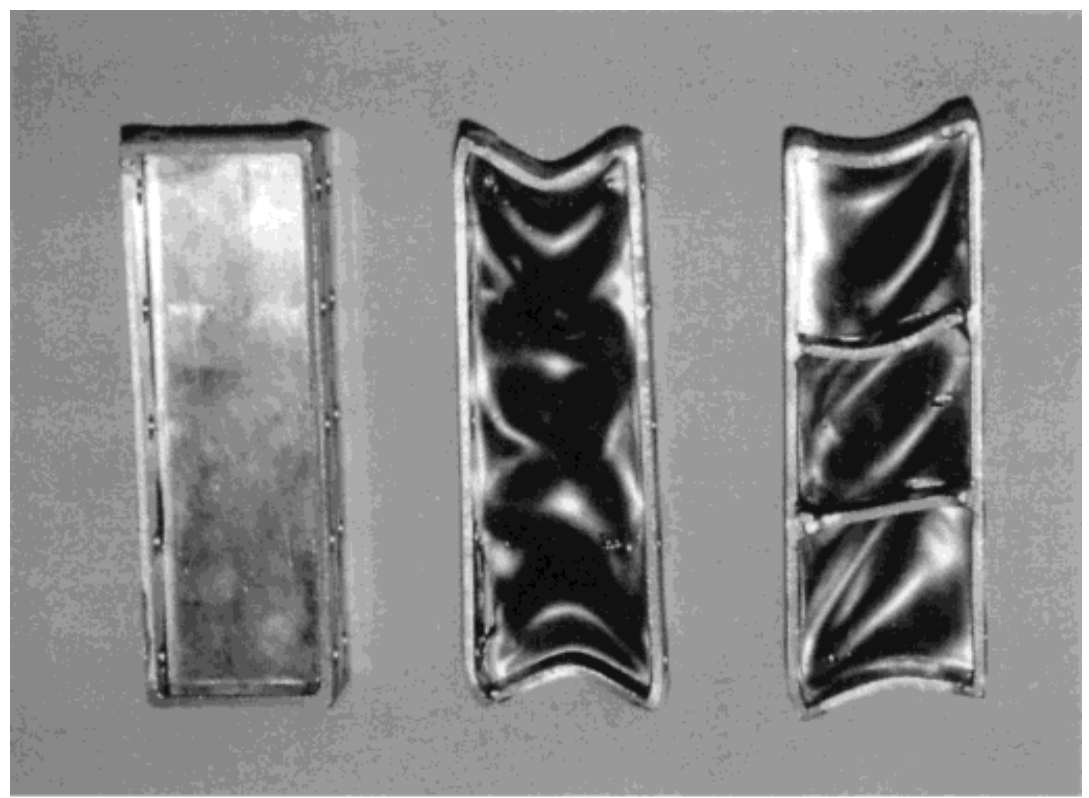

(a)

(b)

(c)

Figure 5. Specimens at the conclusion of testing

the connection between the specimen and the loading fixture. The yielded and buckled specimens at the end of testing are shown in Figure 5(b).

Specimen 3 was identical to specimen 2, except that it had two intermediate stiffeners in addition to the end stiffeners. As expected, the prebuckling elastic and inelastic response was the same as in specimen 2. At larger strains, the intermediate stiffeners were somewhat effective in controlling the plastic web buckling. One buckle initially formed in each panel, but at the $0 \cdot 2$ strain cycles, the intermediate stiffeners were forced to 


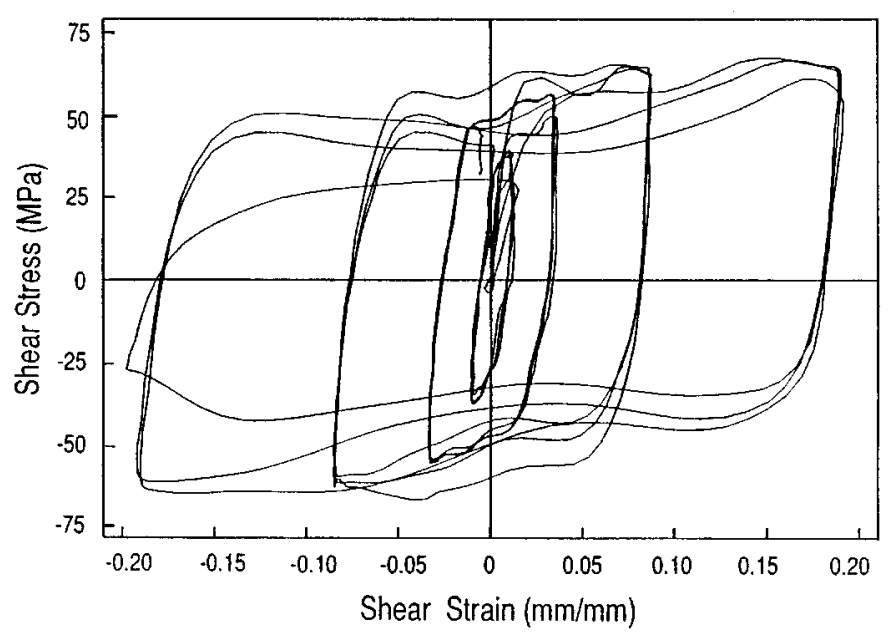

Figure 6. Typical hysteretic behaviour of shear-link at faster strain rate $(10 \mathrm{~Hz})$

move away from the web by deep buckles that passed under them and extended to adjacent panels (see Figure 5(c)). These intermediate stiffeners were not welded to the web and, therefore, could not create shorter effective panel zones to confine the web buckles at larger strains. The observed peak stress was $57 \cdot 7 \mathrm{MPa}$, which was only 4.7 per cent larger than that of specimen 2 .

Specimen 6 had 6061 web material and two intermediate stiffeners in addition to end stiffeners. The specimen showed considerably larger strain hardening at each level of strain when compared to specimen 3; the peak stress of $72.8 \mathrm{MPa}$ is $15 \cdot 1 \mathrm{MPa}$ above the peak of specimen 3. However, the strength of the specimen degraded rather significantly during the $0 \cdot 2$ strain cycles and at a rate faster than that of specimen 3 .

\section{Dynamic (strain rate) cyclic tests}

A typical shear stress-strain behaviour of the shear-link (specimen 11) tested at a strain rate varying from $0 \cdot 2$ to 8 strain/s is shown in Figure 6 . As in the slow tests, noticeable plastic web buckling was observed at $0 \cdot 1$ strain and the loops remained stable until this stage. Moreover, the rapid degradation of strength was observed at 0.2 strain. Similar strain hardening of the loading peaks with increasing strains were also observed. At the conclusion of the tests, specimens tested at faster rates were more visibly distressed than the ones tested quasi-statically. Relatively, large out-of-plane displacement and severe to moderate tearing of the web along the flanges were noted.

\section{ANALYSIS OF TEST RESULTS}

\section{Effect of stiffeners}

Tests of specimen 1 with no stiffeners demonstrated the need of web stiffeners at the ends of all shear-links to resist the transverse compressive forces, which were due to bending moment applied to link flanges. The effect of intermediate stiffeners is shown in Figure 7 wherein some improvement in the larger cycles can be seen, even though the intermediate stiffeners would have been more effective had they been welded to the web. As expected, the addition of transverse stiffeners had little effect on the elastic or inelastic prebuckling behaviour of shear-links. However, the addition of stiffeners, especially end stiffeners did help form a cyclical diagonal tension field by developing a Pratt truss action between the flanges, stiffeners and web, thereby achieving stable hysteretic behaviour. 


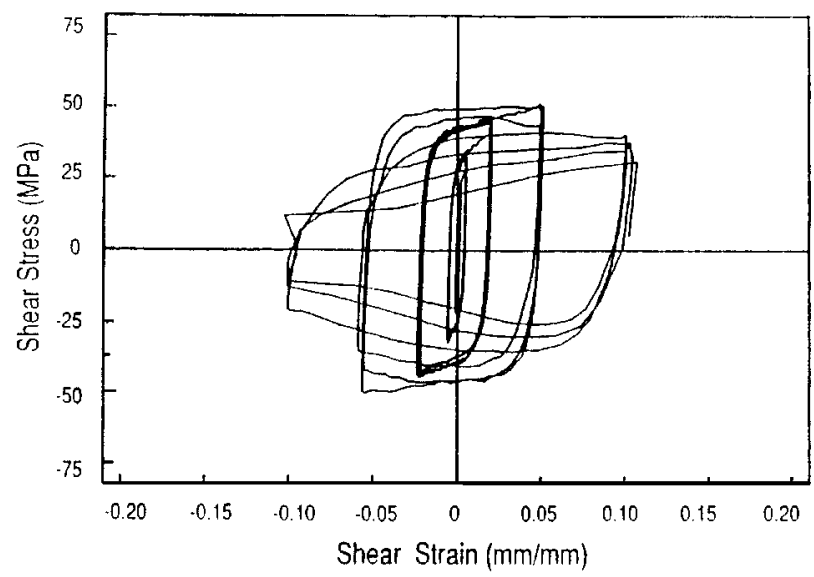

(a)

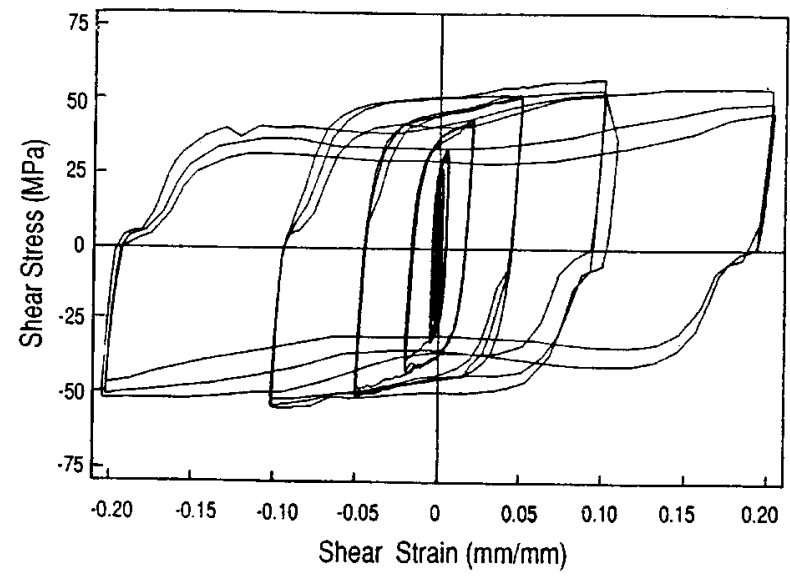

(b)

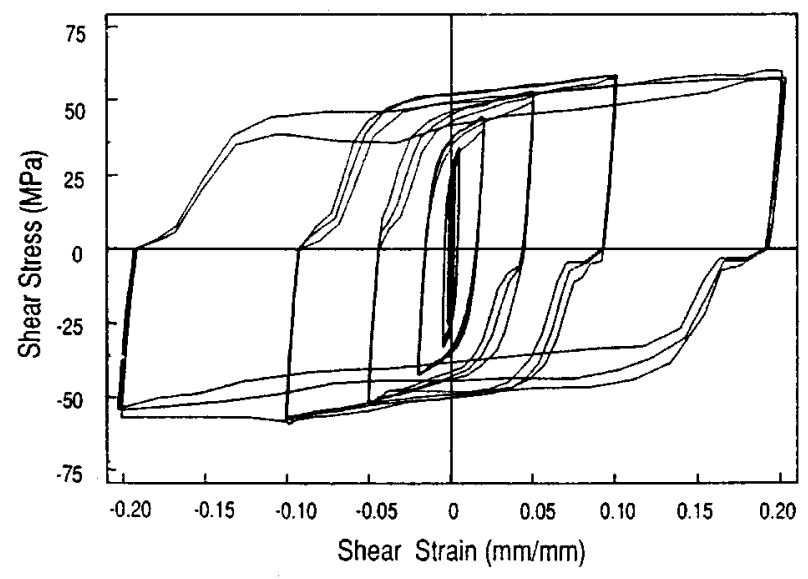

(c)

Figure 7. Comparison of the response of two web stiffening schemes: (a) no stiffener; (b) end stiffeners only; and (b) end and intermediate stiffeners 


\section{Effect of different alloys}

The effect of the stronger web material can be seen in Figure 8, which compares the response of specimen 3 , with 3003 web material, to that of an otherwise identical specimen with stronger, 6061 web material. The relative strain hardening was very similar for both alloys, though the 6061 material resulted in a stronger web. The additional strength of 6061 is a disadvantage, since the link strength needs to be controlled to avoid the inelastic activity in primary structural members. In both cases, rapid deterioration of the link's hysteretic properties was observed at $0 \cdot 2$ strain. From this observation, one can conclude that the 6061 alloy is not superior to the softer 3003 alloy in this application.

\section{Energy dissipation}

Since the success of the structural system is largely dependent on the ability of the shear-link to function most effectively as an energy dissipater, energy dissipation capacity is the primary means of measuring the performance of these links. The area under the hysteresis loop is the amount of energy dissipated by the

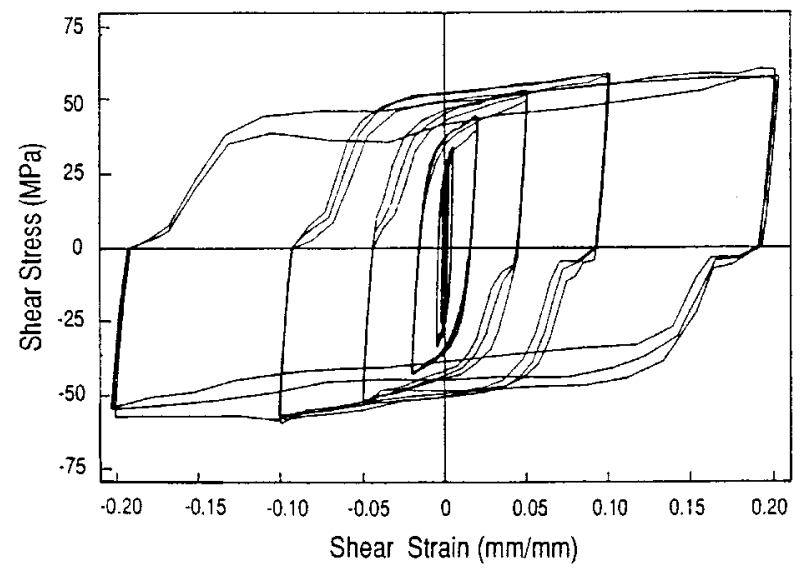

(a)

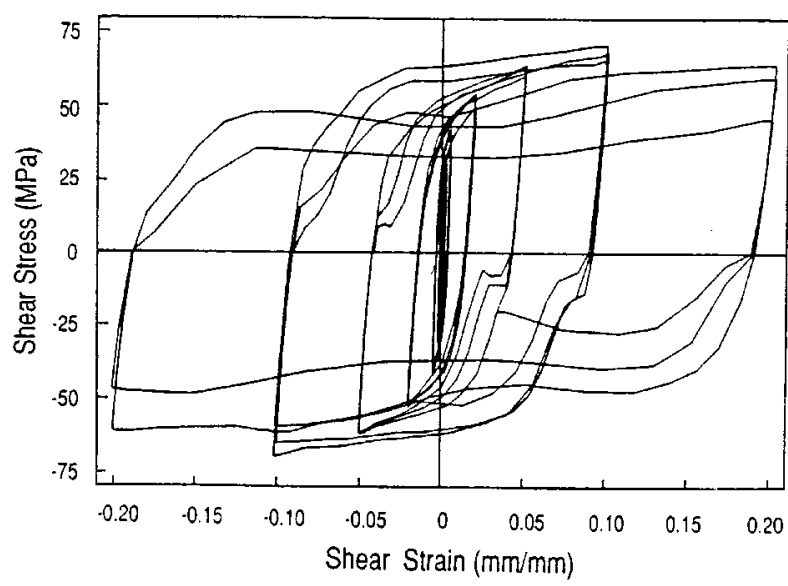

(b)

Figure 8. Comparison of the response of two different web materials: (a) 3003-O; and (b) 6061-O 


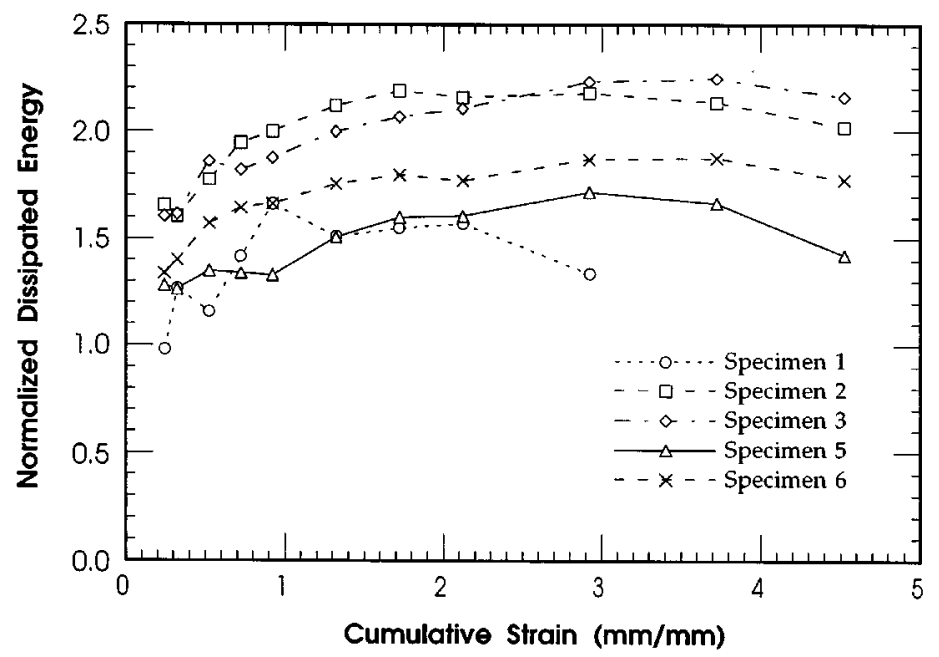

Figure 9. Energy dissipation in shear-links with cumulative strain

shear-links. In Figure 9, the normalized dissipated energy is plotted against the cumulative strain. Dissipated energy is normalized by dividing the energy dissipated in each cycle by the energy which would have been dissipated by an elastic-perfectly plastic shear-link, with the yield load taken from the first inelastic cycle.

As shown in Figure 9, both materials exhibited an excellent strain-hardening characteristic which led to a normalized energy dissipation always greater than 1 . Unlike specimen 1 , the stiffened specimens 2, 3, 5, and 6 demonstrated fairly stable energy dissipation over a wide range of strains. The effect of intermediate stiffeners to increase the energy dissipation capacity of the latter cycles is seen by comparing the results of specimens 2 to 3 and 5 to 6 . Comparison of the curves of 6061 specimens 5 and 6 with 3003 specimens 2 and suggest the superiority of the 3003 alloy over 6061. The curves for 6061 material plot lower than those from 3003 because of a more severely pinched hysteresis loops following the buckling of web. For all specimens, the point at which energy dissipation begins to drop corresponds to the point where major web buckling causes significantly large out-of-plane web deformation.

\section{Strain rate effects}

For comparison purposes, the hysteresis loops of specimens tested at $0 \cdot 01,5$ and $17 \mathrm{~Hz}$ are plotted in Figure 10(a). Irrespective of the cycling frequency, noticeable web buckling was observed at $0 \cdot 1$ strain where the loops remained stable. Instability and rapid degradation of strength was observed at the next cycle of $0 \cdot 2$ strain. A pattern of increasing peak stresses with increasing peak strain rates is noted at all strain levels, as shown in Figure 10(b). A maximum increase of 13 per cent was observed from the lowest frequency $(0 \cdot 01 \mathrm{~Hz})$ to the highest frequency $(17 \mathrm{~Hz})$ at $0 \cdot 1$ strain level. Figure 10 shows that strain rate is not significant in the energy dissipation of aluminium shear-links.

\section{MECHANICAL CHARACTERISTICS OF SHEAR-LINKS}

The experimental data obtained from the cyclic load tests performed on the isolated shear-links models is used to extrapolate the salient design characteristics of shear-links, as discussed below. 


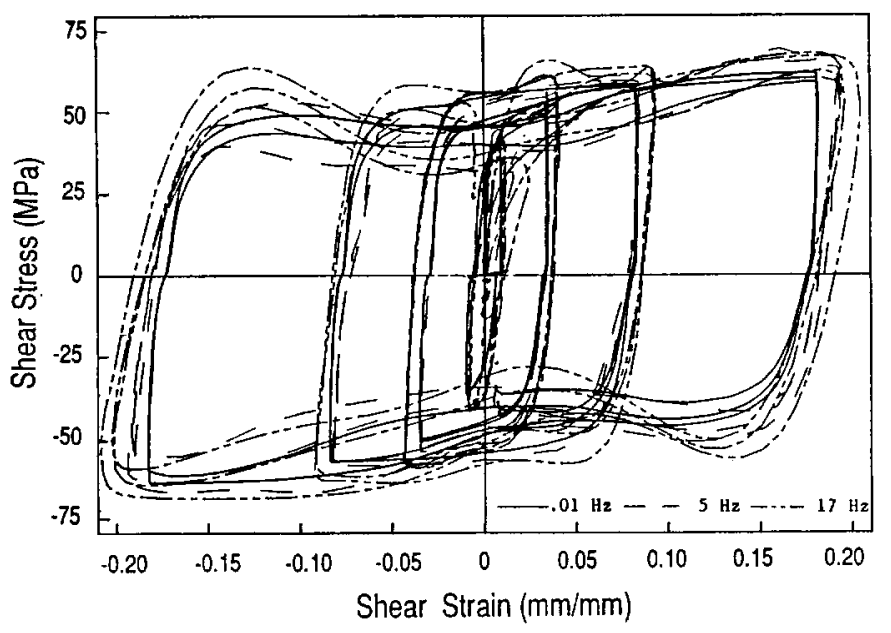

(a)

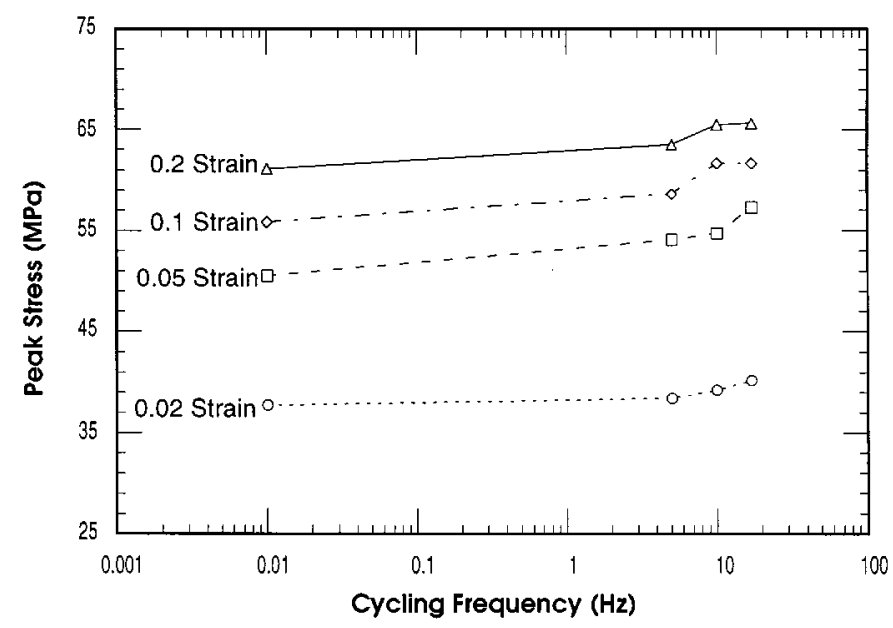

(b)

Figure 10. Effect of strain rates on shear-links: (a) hysteretic behaviour of shear-links at three different frequencies; and (b) influence of cycling frequency on the peak stresses

\section{Force-deformation relationship}

Shear force $R$ and shear deformation $\Delta$ of a shear-link is related to shear stress $\tau$ and shear strain $\gamma$ as follows:

$$
R=\tau A_{\mathrm{w}}
$$

and

$$
\Delta=\gamma d
$$

where $A_{\mathrm{w}}$ is the horizontal web area (i.e. link length $l$ times web thickness $t_{\mathrm{w}}$ ) and $d$ is the depth of I-shaped shear-links. The force-deformation relation of a shear-link can be obtained from their normalized cyclic peak shear strengths $\tau_{\max }$ at various strain levels, as shown in Table III. These shear strengths are normalized 
Table III. Normalized peak shear stress at various strain levels

\begin{tabular}{|c|c|c|c|c|c|c|}
\hline \multirow[b]{2}{*}{$\begin{array}{c}\text { Specimen } \\
\text { no. } \\
(1)\end{array}$} & \multicolumn{6}{|c|}{ Normalized peak shear stress $\left(\tau_{\max } / \sigma_{0 \cdot 2}{ }^{*}\right)$} \\
\hline & $\begin{array}{c}0.002 \\
\text { strain } \\
(2)\end{array}$ & $\begin{array}{l}0 \cdot 005 \\
\text { strain } \\
(3)\end{array}$ & $\begin{array}{l}0 \cdot 02 \\
\text { strain } \\
\quad(4)\end{array}$ & $\begin{array}{c}0 \cdot 05 \\
\text { strain } \\
(5)\end{array}$ & $\begin{array}{c}0 \cdot 1 \\
\text { strain } \\
(6)\end{array}$ & $\begin{array}{c}0 \cdot 2 \\
\text { strain } \\
(7)\end{array}$ \\
\hline 1 & 0.594 & $0 \cdot 836$ & $1 \cdot 163$ & $1 \cdot 317$ & - & - \\
\hline 2 & 0.742 & 0.914 & $1 \cdot 193$ & $1 \cdot 439$ & $1 \cdot 565$ & $1 \cdot 459$ \\
\hline 3 & 0.831 & $1 \cdot 076$ & $1 \cdot 200$ & $1 \cdot 446$ & $1 \cdot 641$ & $1 \cdot 601$ \\
\hline 7 & - & - & - & $1 \cdot 529$ & 1702 & $1 \cdot 838$ \\
\hline 8 & - & - & $1 \cdot 108$ & $1 \cdot 561$ & 1.670 & $1 \cdot 838$ \\
\hline 9 & - & - & $1 \cdot 076$ & $1 \cdot 525$ & $1 \cdot 622$ & 1795 \\
\hline 10 & - & - & $1 \cdot 149$ & $1 \cdot 565$ & $1 \cdot 847$ & $1 \cdot 881$ \\
\hline 11 & - & - & $1 \cdot 080$ & $1 \cdot 547$ & 1.784 & $1 \cdot 841$ \\
\hline 12 & - & - & $1 \cdot 153$ & 1.639 & $1 \cdot 710$ & $1 \cdot 861$ \\
\hline 13 & - & - & $1 \cdot 073$ & $1 \cdot 437$ & $1 \cdot 583$ & 1.736 \\
\hline 14 & - & - & $1 \cdot 133$ & $1 \cdot 618$ & 1.793 & $1 \cdot 866$ \\
\hline Avg. & 0.722 & 0.942 & $1 \cdot 133$ & $1 \cdot 511$ & 1.692 & $1 \cdot 866$ \\
\hline $\operatorname{COV}(\%)$ & $13 \cdot 6$ & $10 \cdot 6$ & $3 \cdot 9$ & $5 \cdot 9$ & $5 \cdot 3$ & $7 \cdot 4$ \\
\hline
\end{tabular}

with the tensile coupon yield stress $\sigma_{0.2}$ of the material. It can be seen that at a given strain amplitude, the shear strength of a link is nearly a constant. All specimens with aluminium 3003-O have been used in this analysis to provide a meaningful data population. The observed variability is due to differences in the stiffener arrangements and the strain rate at which the shear-links were cycled.

These peak shear stress values can be well described by a power law relating the average peak shear stresses $\tau_{\text {avg, max }}$ to shear strains $\gamma$ in terms of the tensile yield strength $\sigma_{0.2}$ of the web material. The data presented in Table III are shown in a $\log -\log$ plot of Figure 11 in which the best fit line approximates the stress-strain relation as follows:

$$
\tau_{\text {avg, } \max }=2 \cdot 6 \sigma_{0 \cdot 2} \gamma^{0 \cdot 2}
$$

This power relation is based on the data up to only $0 \cdot 2$ shear strain and cannot be predicted for larger strains. This value will be taken as the upper limit of the maximum deformation allowable in shear-links. Equation (3) is used to obtain the average shear stress at any given strain.

\section{Cyclic web buckling and stiffener spacing}

The cyclic test of 14 shear links demonstrated that thick web specimens avoided the elastic web buckling problem as expected. However, plastic web buckling was observed in all specimens at cycles of $0 \cdot 1$ strain, which is associated with a reduction in energy dissipation capacity, which can be prevented by using transverse web stiffeners. The solution to the plastic cyclic web buckling problem can be obtained by modifying the solutions obtained for monotonic cases, considering the similarity of the web buckling modes. ${ }^{8}$ The approach followed is similar to what Gerard ${ }^{9}$ developed for the plate problem. Additionally, the plastic web buckling problem has been formulated as being analogous to the elastic buckling problem and can be expressed as ${ }^{10}$

$$
\tau=\eta(\tau) \tau_{\mathrm{E}}
$$




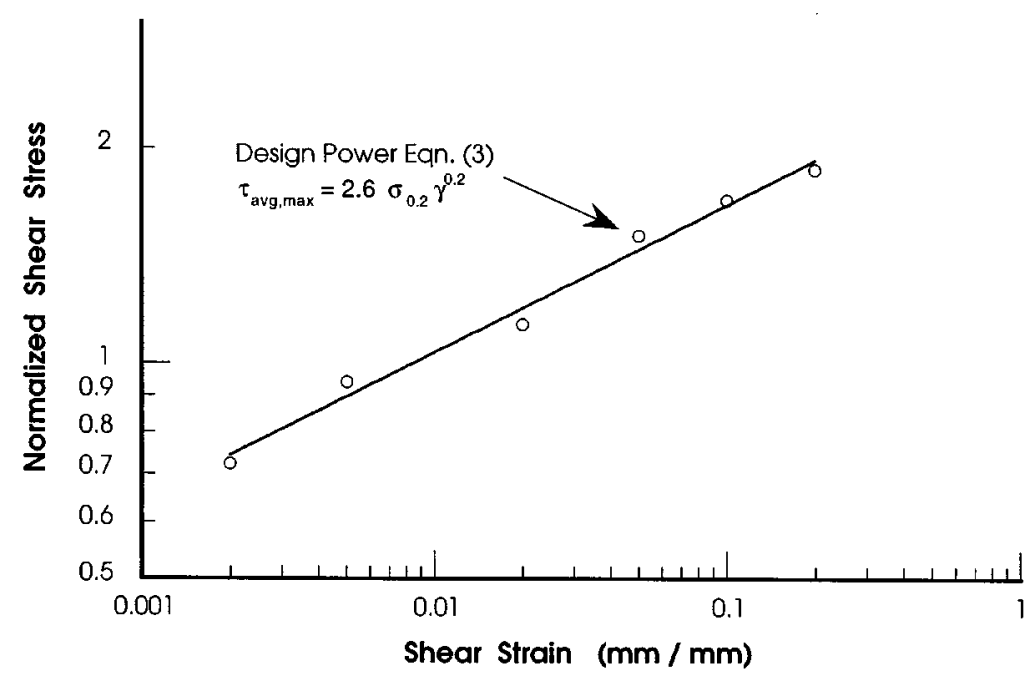

Figure 11. Peak shear stress-strain relation and the governing design equation

where $\eta(\tau)$ is the plastic-reduction factor which is related to post-elastic behaviour of the plate, and $\tau_{\mathrm{E}}$ is an elastic buckling stress given by

$$
\tau_{\mathrm{E}}=k_{\mathrm{s}} \frac{\pi^{2} E}{12\left(1-v^{2}\right)}\left(\frac{1}{\beta}\right)^{2}
$$

where $E$ is Young's modulus, $v$ is Poission's ratio, $\beta$ is the web depth-to-thickness ratio, and $k_{s}$ is the buckling coefficient which relates shear buckling stress to the aspect ratio $\alpha$ of the web panel formed by the transverse stiffeners and the condition of the edge support. $\alpha$ is defined as the ratio of stiffener spacing $a$ to the clear depth of link beam $\left(d_{\mathrm{w}}=d-2 t_{\mathrm{f}}\right)$, where $t_{\mathrm{f}}$ is the thickness of the flange. It is reasonable to assume clamped end conditions for the web panel, as the stiffeners welded to the web and the flanges of a rolled section provide significant restraint to the web. In that case $k_{\mathrm{s}}$ is given by

$$
k_{\mathrm{s}}= \begin{cases}5.6+\frac{8.98}{\alpha^{2}} & \text { for }(\alpha \leqslant 1) \\ 8.98+\frac{5.6}{\alpha^{2}} & \text { for }(\alpha \geqslant 1)\end{cases}
$$

An experimental value for the plastic reduction factor $\eta$ can be obtained from equation (4) by substituting $\tau=\tau_{\mathrm{b}}$ at the buckling stage for each of the shear links, as shown in Table IV. Gerard proposed an empirical expression for $\eta$ as a function of the ratio of secant modulus $G_{\mathrm{s}}$ and shear modulus $G$ of the shear-link, i.e.

$$
\eta=f \frac{G_{\mathrm{s}}}{G}
$$

where $f$ is the proportionality constant and $G_{\mathrm{s}}$ is defined as (see Figure 12)

$$
G_{\mathrm{s}}=\frac{\tau}{\bar{\gamma}}
$$


Table IV. Plastic web buckling of shear-links

\begin{tabular}{cccccc}
\hline $\begin{array}{c}\text { Specimen } \\
\text { no. } \\
(1)\end{array}$ & $\begin{array}{c}\tau_{\mathrm{b}}{ }^{*} \\
(\mathrm{MPa})\end{array}$ & $\begin{array}{c}G_{\mathrm{s}}=\tau_{\mathrm{b}} / \bar{\gamma}^{\dagger} \\
(\mathrm{MPa})\end{array}$ & $\begin{array}{c}G_{\mathrm{s}} / G^{\ddagger} \\
(3)\end{array}$ & $\begin{array}{c}\tau_{\mathrm{b}} / \tau_{\mathrm{E}}{ }^{\S} \\
(5)\end{array}$ & $\begin{array}{c}f \\
(5) /(4) \\
(6)\end{array}$ \\
\hline 2 & $55 \cdot 1$ & $367 \cdot 3$ & $0 \cdot 0141$ & $0 \cdot 0531$ & $3 \cdot 7660$ \\
7 & $59 \cdot 9$ & $399 \cdot 3$ & $0 \cdot 0154$ & $0 \cdot 0577$ & $3 \cdot 7468$ \\
8 & $58 \cdot 8$ & $392 \cdot 0$ & $0 \cdot 0146$ & $0 \cdot 0567$ & $3 \cdot 8836$ \\
9 & $57 \cdot 1$ & $380 \cdot 7$ & $0 \cdot 0151$ & $0 \cdot 0550$ & $3 \cdot 6426$ \\
10 & $65 \cdot 0$ & $433 \cdot 3$ & $0 \cdot 0167$ & $0 \cdot 0626$ & $3 \cdot 7485$ \\
11 & $62 \cdot 8$ & $418 \cdot 7$ & $0 \cdot 0161$ & $0 \cdot 0605$ & $3 \cdot 7578$ \\
12 & $60 \cdot 2$ & $401 \cdot 3$ & $0 \cdot 0154$ & $0 \cdot 0580$ & $3 \cdot 7662$ \\
13 & $55 \cdot 7$ & $371 \cdot 3$ & $0 \cdot 0143$ & $0 \cdot 0537$ & $3 \cdot 7552$ \\
14 & $63 \cdot 1$ & $420 \cdot 7$ & $0 \cdot 0162$ & $0 \cdot 0608$ & $3 \cdot 7531$ \\
Avg. & & & & & 3.7578 \\
\hline
\end{tabular}

* Experimental value of plastic web buckling. Peak shear stress at 0.1 strain of Column (6) of Table III with $\sigma_{0 \cdot 2}=35 \cdot 2 \mathrm{MPa}$

${ }^{\dagger} \bar{\gamma}=0 \cdot 15(\mathrm{~mm} / \mathrm{mm})$

${ }^{\ddagger} G=$ Shear modulus of aluminium $=26 \mathrm{GPa}$

${ }^{\S} \tau_{\mathrm{E}}=$ Elastic buckling stress $=1038 \mathrm{MPa}\left(a=146 \mathrm{~mm}, d_{\mathrm{w}}=45 \cdot 2 \mathrm{~mm}, t_{\mathrm{w}}=\right.$ $\left.1.6 \mathrm{~mm}, b=38.8 \mathrm{~mm}, \alpha=3.7629, \beta=24.25, k_{\mathrm{s}}=9.375, E=70 \mathrm{GPa}\right)$

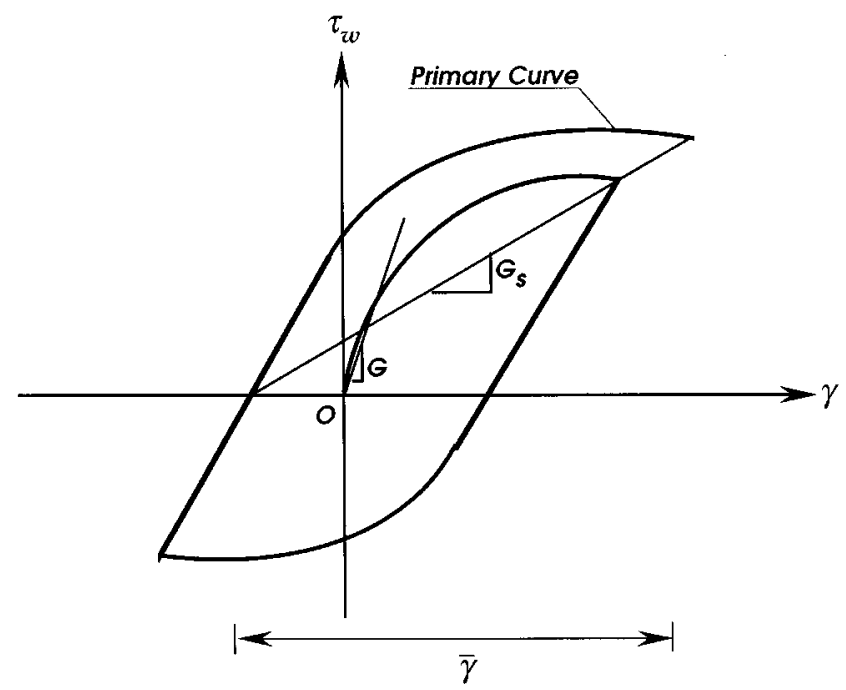

Figure 12. Definition of secant shear modulus, $G_{\mathrm{s}}$ and link deformation angle, $\bar{\gamma}$

In all specimens, the buckling was first observed during the first excursion of $0 \cdot 1$ strain cycle following cycles of 0.05 strain, which means that $\bar{\gamma}$ at the buckling was $0 \cdot 15$. The values of the ratio $G_{\mathrm{s}} / G$ and proportionality factor $f$ is calculated for each specimen as shown in Table IV. Using an average value of $f$ equal to 3.76, equation (7) becomes

$$
\eta=3 \cdot 76 \frac{G_{\mathrm{s}}}{G}
$$


The expression for $\eta$ is purely a function of strain-hardening properties of the material, an observation which agrees with the study of Kasai and Popov ${ }^{8}$ concerning shear link beams of eccentrically braced frames. Substituting equation (9) into equation (4), with $\tau=\tau_{\mathrm{b}}$ at the buckling stage, we obtain

$$
\tau_{\mathrm{b}}=3 \cdot 76 \frac{G_{\mathrm{s}}}{G} \tau_{\mathrm{E}}
$$

Substituting equation (8) with $\tau=\tau_{\mathrm{b}}$ and $\bar{\gamma}=\bar{\gamma}_{\mathrm{b}}$ at the buckling stage, $\bar{\gamma}_{\mathrm{b}}$ can be obtained as

$$
\bar{\gamma}_{\mathrm{b}}=3.76 \frac{\tau_{\mathrm{E}}}{G}
$$

Substituting equation (5) into equation (11) and taking $v=0 \cdot 34$, equation (11) can be simplified to

$$
\bar{\gamma}_{\mathrm{b}}=9 \cdot 37 \frac{k_{\mathrm{s}}}{\beta^{2}}
$$

Equation (12) is a simple relationship connecting the web buckling deformation angle $\bar{\gamma}_{\mathrm{b}}$ to the web panel aspect ratio $\alpha$ and the web panel depth-to-thickness ratio $\beta$. It can be used to determine the spacing of transverse stiffeners to avoid web buckling at the design load by taking $\bar{\gamma}_{\mathrm{b}}$ equal to two times of $\gamma_{\mathrm{d}}$, the web deformation angle at the design load.

\section{Design requirements for stiffeners}

To allow shear-links to maintain their post-buckling capacities, each transverse stiffener is proportioned to avoid the possibility of local buckling within the stiffener and must remain effective after the web buckles to support the tension field as well as to prevent the tendency of flanges to move towards each other. This means stiffeners must meet stiffness and stability checks. The stiffness check is satisfied if the moment of inertia of stiffener about its centroidal axis parallel to the web is not less than $j \xi a\left(t_{\mathrm{w}}\right)^{3}$ where

$$
j=\left\{2 \cdot 5 /\left(a / d_{\mathrm{w}}\right)^{2}-2\right\} \geqslant 0 \cdot 5
$$

$a$ is the distance between the transverse stiffeners and $\xi$ is an amplifying coefficient to account for post-buckling strength and a value of 4 is suggested for an open-section stiffener. For stability check, the stiffener is designed as a compression strut for an axial force equal to $0 \cdot 3$ times the factored shear load. ${ }^{11}$ The stiffener thickness $t_{\mathrm{w}}$ should be not less than $10 \mathrm{~mm}$, and the width should be $\left(b_{\mathrm{f}} / 2\right)-t_{\mathrm{w}}$, where $b_{\mathrm{f}}$ is the flange width of the link beam.

\section{PART II: SEISMIC PERFORMANCE OF ALUMINIUM SHEAR-LINK BRACING FRAME SYSTEM}

\section{DESIGN OF SHEAR-LINK BRACED FRAME (SLBF) SYSTEM}

The braces in the SLBF system are proportioned to avoid buckling by letting shear-links yield first and then dissipating the input energy during inelastic excursions before they reach their maximum usable shear strength. The shear-links are designed on the basis of the two limit states corresponding to strength and ductility demands of the design level and maximum credible earthquakes. The size of each shear-link was determined by calculating the horizontal area of the web required to resist the design storey shear. The web area was obtained by dividing the storey shear by the value of shear stress corresponding to a limiting value of shear strain. This shear strain can be taken to correspond to the allowable storey drift but cannot exceed $0 \cdot 1$ strain because the links were observed to have excellent load-carrying capacity and hysteretic characteristics below this strain level. In other words, 'design' shear stress to proportion shear-links is obtained from 
equation (3) at 'design' shear strain of $\gamma_{\mathrm{d}}$ which is given as

$$
\gamma_{\mathrm{d}}=\frac{\delta}{d} \leqslant 0 \cdot 1
$$

where $\delta$ is allowable storey drift and $d$ is the depth of shear link which can be taken to be in the range of $1 / 10-1 / 12$ of storey height $h_{n}$.

It is essential for the satisfactory performance of the SLBF system that when the shear-links reach their maximum shear strength, the axial forces in the braces must be less than their buckling loads. The maximumallowable shear strength of shear-links is assumed to correspond to 20 per cent shear strain, and a strain higher than this is assumed to represent the failure of shear-links. Based on the data in Table III, the maximum shear capacity can be taken as 1.88 times the tensile yield stress $\sigma_{0.2}$ of the material.

Link stiffeners on both sides of the web are required to prevent plastic buckling of the web and to ensure a ductile shear failure of the web. Transverse stiffeners must be provided at each end of the link and, if required, intermediate stiffeners should be provided at regular intervals within the link such that equation (12) is satisfied. Taking the maximum allowable value of $\bar{\gamma}_{\mathrm{b}}=2 \gamma_{\mathrm{d}}=0.2$ and the lower bound value of $k_{\mathrm{s}}$ as 8.98 in equation (12), it can be shown that intermediate stiffeners are not needed when the web depth-tothickness ratio $\beta$ of link is less than 20 .

\section{TYPICAL DESIGN BUILDING}

A four-storey office building is assumed to be located in the UBC Seismic Zone 4 on the soil profile $S_{2}$. In the plan, the building is $42.7 \mathrm{~m}$ long in the E-W direction (6 bays @ 7.1 m) and $42.7 \mathrm{~m}(5$ bays @ $8.53 \mathrm{~m})$ wide in the N-S direction. As for elevation, floor-to-floor heights are $4.25 \mathrm{~m}$ and the building is assumed to possess no irregularity of any kind. The typical framing plan of the building is shown in Figure 13(a). In the E-W direction, moment resisting frames 1 and 6 along the perimeter resist the lateral forces in that direction while

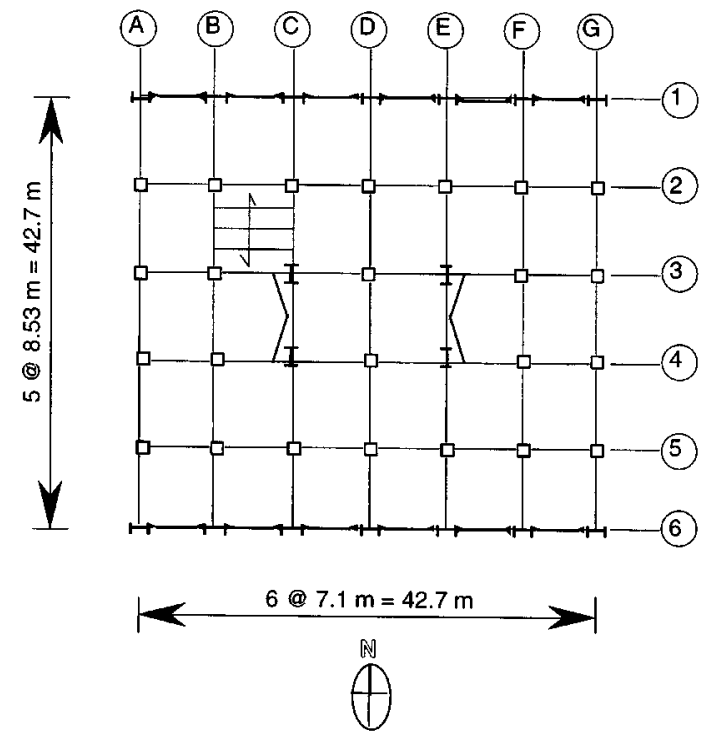

(a)

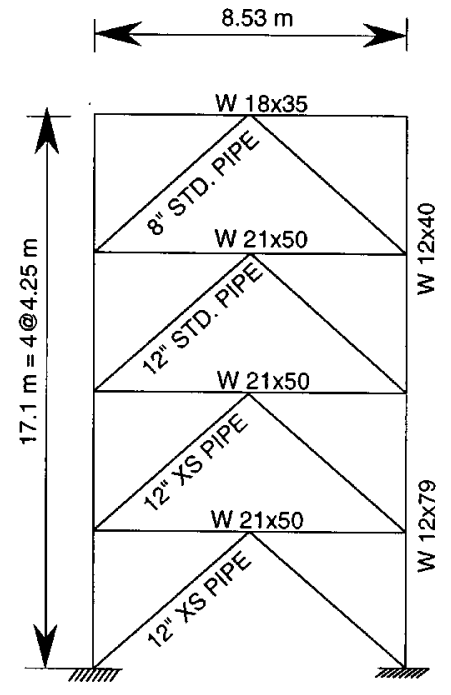

(b)

Figure 13. (a) Plan of the four-storey study building; and (b) OCBF members designed for the UBC lateral seismic forces 
Table V. Lateral design seismic forces

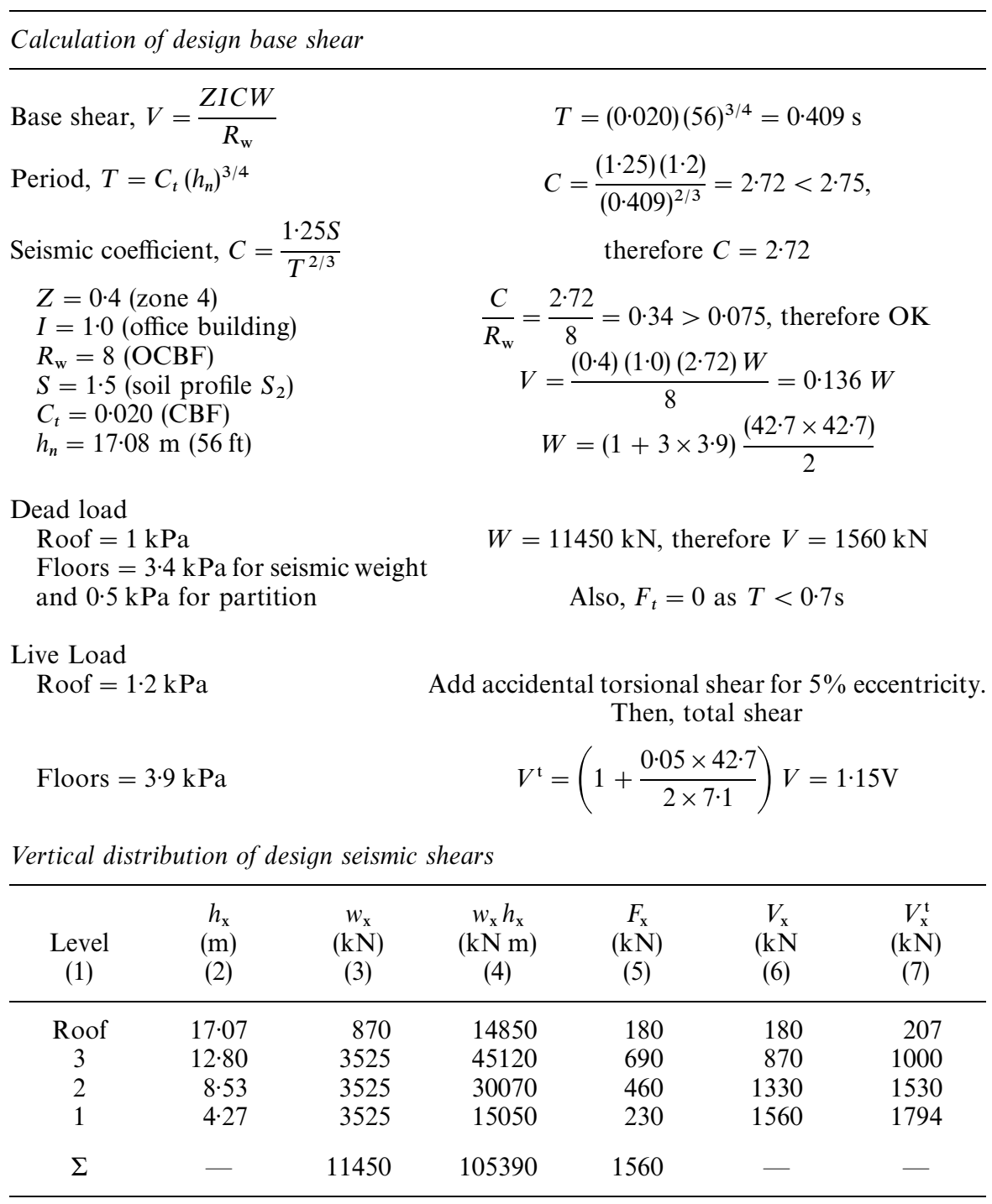

in the $\mathrm{N}-\mathrm{S}$ direction, two bracing frame systems are designed to provide the Code level seismic lateral resistance. These frames will be placed symmetrically along the line $\mathrm{C}$ and $\mathrm{E}$, separated by two bay-widths as shown in Figure 13(a). The other interior frames are designed to resist only gravity loads associated with their tributary areas. The calculation of the design base shear and the storey shears are summarized in Table V.

\section{Ordinary chevron bracing frame}

The conventional Chevron-type OCBF is designed in accordance with UBC (1994) and shown in Figure 13(b). The columns and girders are of A572 $\left(f_{\mathrm{y}}=345 \mathrm{MPa}\right)$ steel while A53 $\left(f_{\mathrm{y}}=240 \mathrm{MPa}\right)$ steel pipe sections are used for braces. Pipe sections are chosen for braces because the fracture life and ductility are greater than those of rectangular tube sections. 
Table VI. Proportioning of shear-links

\begin{tabular}{|c|c|c|c|c|c|c|c|c|}
\hline \multirow[b]{2}{*}{$\begin{array}{l}\text { Storey } \\
\text { (1) }\end{array}$} & \multirow{2}{*}{$\begin{array}{c}\text { Design } \\
\text { storey } \\
\text { shear } \\
(\mathrm{kN}) \\
(2)\end{array}$} & \multirow{2}{*}{$\begin{array}{c}\text { Design } \\
\text { shear } \\
\text { strain } \\
\gamma_{\mathrm{d}} \\
(3)\end{array}$} & \multirow{2}{*}{$\begin{array}{c}\text { Design } \\
\text { shear } \\
\text { stress } \\
(\mathrm{MPa}) \\
\text { (4) }\end{array}$} & \multirow{2}{*}{$\begin{array}{c}\text { Eqivalent } \\
\text { Equivalent } \\
\text { AISC } \\
\text { W-section } \\
(5)\end{array}$} & \multicolumn{3}{|c|}{$\begin{array}{l}\text { Length, depth and web } \\
\text { thickness }\end{array}$} & \multirow{2}{*}{$\begin{array}{l}\text { Shear } \\
\text { strength } \\
\text { provided } \\
(\mathrm{kN}) \\
(9)\end{array}$} \\
\hline & & & & & $\begin{array}{c}l \\
(\mathrm{~mm}) \\
(6)\end{array}$ & $\begin{array}{c}d \\
(\mathrm{~mm}) \\
(7)\end{array}$ & $\begin{array}{c}t_{\mathrm{w}} \\
(\mathrm{mm}) \\
(8)\end{array}$ & \\
\hline $\begin{array}{l}\text { First and } \\
\text { second }\end{array}$ & 1833 & $0 \cdot 06^{*}$ & $52 \cdot 1$ & W $12 \times 170$ & 1525 & $355 \cdot 6$ & $24 \cdot 4$ & 2460 \\
\hline $\begin{array}{l}\text { Third and } \\
\text { fourth }\end{array}$ & 1023 & $0 \cdot 06$ & & W $12 \times 170$ & 815 & $355 \cdot 6$ & $24 \cdot 4$ & 1310 \\
\hline
\end{tabular}

* Corresponds to allowable storey drift of 0.005 times storey height

Table VII. Overstrength factor provided against brace buckling

\begin{tabular}{|c|c|c|c|c|c|}
\hline $\begin{array}{c}\text { Storey } \\
\text { (1) }\end{array}$ & $\begin{array}{c}\text { Brace size } \\
\text { AISC pipe } \\
\text { section } \\
(2)\end{array}$ & $\begin{array}{c}\text { Brace } \\
\text { buckling } \\
\text { Force, } \\
P_{\mathrm{cr}}^{*} \\
(\mathrm{kN}) \\
(3)\end{array}$ & $\begin{array}{c}\text { Buckling } \\
\text { shear } \\
V_{\mathrm{cr}}^{\dagger} \\
(\mathrm{kN}) \\
(4)\end{array}$ & $\begin{array}{c}\text { Max. } \\
\text { shear-link } \\
\text { strength, } \\
R_{\max }^{\ddagger} \\
(\mathrm{kN}) \\
(5)\end{array}$ & $\begin{array}{l}\text { Overstrength } \\
\text { factor } \\
V_{\mathrm{cr}} / R_{\max } \\
\text { (6) }\end{array}$ \\
\hline First and Second & $2^{\prime \prime} \mathrm{XS}$ & 2535 & 3585 & 2460 & $1 \cdot 46$ \\
\hline Third & $12^{\prime \prime} \mathrm{Std}$ & 1485 & 2099 & 1312 & $1 \cdot 60$ \\
\hline Fourth & 8" Std. & 952 & 1348 & 1312 & $1 \cdot 03$ \\
\hline
\end{tabular}

\section{Shear-link bracing frame}

The design storey shears for the SLBF were kept the same as the ones used for the OCBF to facilitate a direct comparison. The calculations related to the proportioning of shear-links are shown in Table VI. Only two sizes of shear-links were provided instead of one for each storey. As web thickness ratio (11.33) is less than 20, intermediate stiffeners are not required; only end transverse stiffeners of thickness $25 \mathrm{~mm}$ and combined width of $270 \mathrm{~mm}$ are provided. Once the shear-links were proportioned, the braces were designed for loads equal to the maximum strength of the shear-links. However, in this study, the braces and other members of the SLBF were kept the same as in the OCBF system to facilitate a direct comparison. As a result, the brace buckling shear exceeded the shear link strength by a factor ranging from 1.03 to 1.60 in various stories, as shown in Table VII.

\section{A SIMPLIFIED HYSTERETIC MODEL OF SHEAR-LINKS}

A simple non-degrading hysteretic model is assumed to represent the shear force-displacement behaviour of shear-links. The model operates on a bilinear skeleton relation between shear force $R$ and displacement 


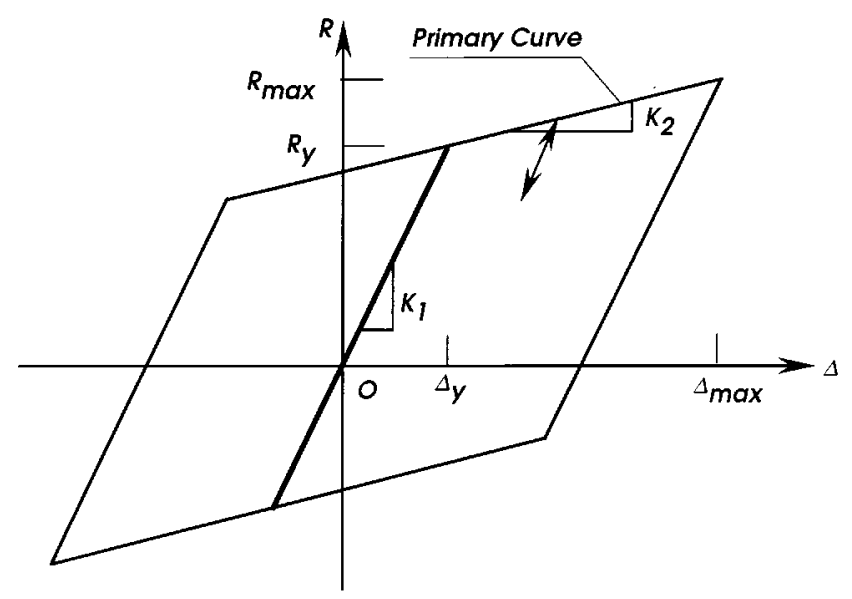

Figure 14. Bi-linear hysteretic model for shear-links used in the study

$\Delta$ which can be exclusively defined by the following three parameters:

1. yield shear force, $R_{\mathrm{y}}$,

2. first stiffness, $K_{1}$, and

3. second stiffness, $K_{2}$, which is often expressed as a percentage of $K_{1}$.

The schematic of the model is shown in Figure 14. The first stiffness is taken as the secant stiffness corresponding to a shear strain of 0.002 at which the general yielding of the shear-link specimens was observed. At this stage the average shear stress was 0.722 times the tensile yield strength $\sigma_{0 \cdot 2}$ (see Table III) and can be taken as the 'yield' shear stress. This value is multiplied by the horizontal web area $A_{\mathrm{w}}$ of the shear-link to give $R_{\mathrm{y}}$. The second stiffness can be easily computed from the fact that the maximum shear force allowed at the shear strain of $0 \cdot 2$ marks the end-point of the second linear branch of the primary curve (see Figure 14). This idealization results in the underestimation of shear force $R$ for relatively smaller displacements, as suggested by the power relation of equation (3). In lieu of this conservative but simple hysteretic model, a more realistic but complex model such as the one proposed in the study by $\mathrm{Rai}^{1}$ can be employed. Basic properties of the two different shear-links used in the building frame are summarized in Table VIII. It is interesting to note that even the secant stiffness of the shear-links is comparable with the lateral stiffness of the Chevron braces. However, the second stiffness is very small in comparison to the first stiffness but is large enough in absolute terms to ensure satisfactory frame response, as will be demonstrated in following sections.

\section{MODELLING IN SNAP-2D}

SNAP-2D is a general purpose computer program for dynamic non-linear analysis of two-dimensional structures. The program formulation is based on a member-to-member modelling approach, i.e. one-to-one correspondence exists between the elements of the model and the members of the structure. The structure is discretized to a group of elements such as beam-columns, braces, shear-links, etc., and element force-deformation properties are specified in the form of the hysteretic response expressed in terms of a force-deformation pair controlling the behaviour of the element. Element 2 of the SNAP-2D element library is used to model all beams and columns while element 9 is used to model the bracing members in both frames. The shear-links are modelled by element 7 with parameters shown in Table VIII. All columns have 
Table VIII. Hysteretic model properties of shear-links

\begin{tabular}{|c|c|c|c|c|c|}
\hline $\begin{array}{l}\text { Shear-links } \\
\text { (1) }\end{array}$ & $\begin{array}{l}\text { Yield shear } \\
\text { force } R_{\mathrm{y}}{ }^{*} \\
(\mathrm{kN}) \\
(2)\end{array}$ & $\begin{array}{c}\text { First stiffness } \\
K_{1} \\
(\mathrm{kN} / \mathrm{mm}) \\
(3)\end{array}$ & $\begin{array}{c}\text { Second stiffness } \\
K_{2} \\
(\mathrm{kN} / \mathrm{mm}) \\
(4)\end{array}$ & $\begin{array}{c}K_{2} \text { as } \\
\text { percentage } \\
\text { of } K_{1} \\
(5)\end{array}$ & $\begin{array}{c}\text { Max. shear } \\
\text { capacity } \\
R_{\max } \\
(\mathrm{kN}) \\
(6)\end{array}$ \\
\hline $\begin{array}{l}\text { First and } \\
\text { second storeys }\end{array}$ & 849 & 1194 & $15 \cdot 3$ & 1.28 & 2210 \\
\hline $\begin{array}{l}\text { Third and } \\
\text { fourth storeys }\end{array}$ & 472 & 663 & 8.6 & 1.29 & 1230 \\
\hline
\end{tabular}

${ }^{*} R_{\mathrm{y}}=\left(0.722 \sigma_{0 \cdot 2}\right) A_{\mathrm{w}}$ where $A_{\mathrm{w}}$ is the horizontal web area of the link, i.e. $l$ times $t_{\mathrm{w}}$

non-moment connections with the beams but are assumed to be continuous and rigidly connected at the base.

\section{PUSHOVER ANALYSES}

Static pushover analyses were carried out to determine ultimate lateral capacities and collapse mechanisms of both frames. Frames were subjected to incremental monotonic lateral loads in the Code assumed inverted triangular storey distribution of loads at all loading steps. The failure mechanism and the location of plastic hinges at collapse are shown in Figure 15(a). Clearly, the OCBF developed a soft storey mechanism with plastic hinging in the first floor girder, as well as brace buckling and column hinging. As seen in Figure 15(b), the SLBF is almost as stiff as the OCBF before yielding of the first-storey shear-link at about 60 per cent of the design base shear. After the first yield, however, the SLBF continued to resist additional shear force through a larger deformation, while the OCBF showed a significantly reduced capacity after brace buckling.

\section{TIME-HISTORY ANALYSES}

\section{Ground motion characteristics}

Four different ground motions were used as base excitations in the time-history response analyses of both frames. Three recorded ground motions of Miyagi-Ken-Oki (1978), El Centro (1940), and Northridge (1994) earthquakes were scaled to a peak ground acceleration (PGA) of $0.26 \mathrm{~g}, 0.38 \mathrm{~g}$, and $0.33 \mathrm{~g}$, respectively, to match the Code assumed 'intensity' of a design level earthquake for this structure. The scaling factor was selected to bring the 5 per cent damped elastic response spectrum of the original earthquake record close to the Code design spectrum for the soil profile $S_{2}$ specified for the dynamic lateral force procedures. The synthetic accelerogram was generated by modifying an earthquake record such that its acceleration spectrum was consistent with the UBC $S_{2}$ design spectrum. Figure 16 compares the UBC $S_{2}$ design spectrum to the scaled spectra of ground motions. El Centro and Northridge earthquake records have a small low-energy content, whereas the synthetic accelerogram is a motion of long duration with a rich frequency content and extremely high-energy content. Miyagi has a narrow band of frequency around $1 \mathrm{~Hz}$ with an intermediate energy content.

\section{Failure mechanism and time-history response}

The location of plastic hinges, brace buckling and shear-link yielding at the end of $20 \mathrm{~s}$ of the Miyagi record is shown in Figure 17. The OCBF developed a soft storey mechanism, whereas the SLBF behaved as 


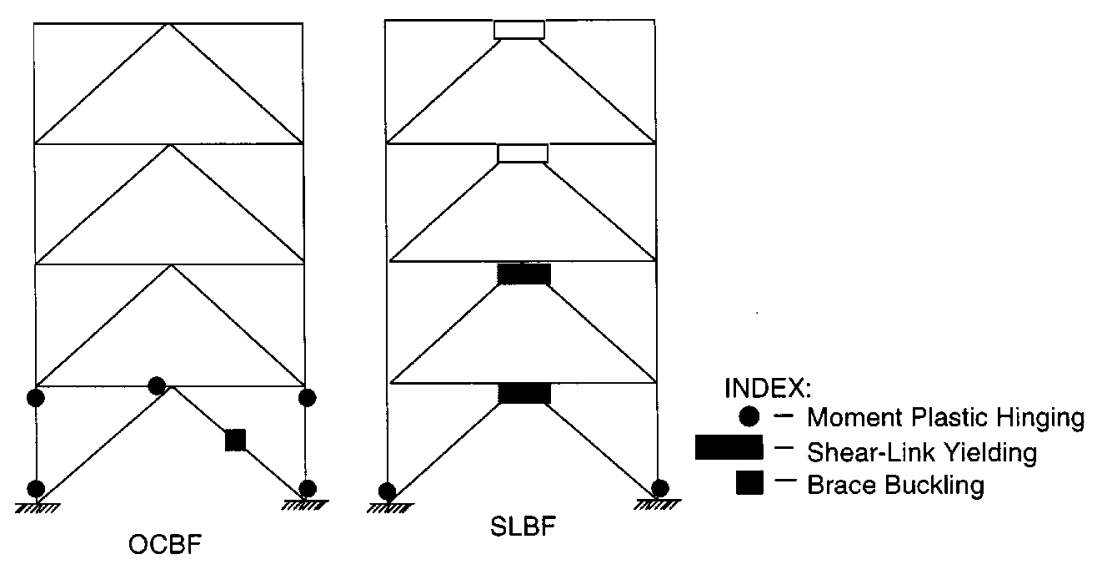

(a)

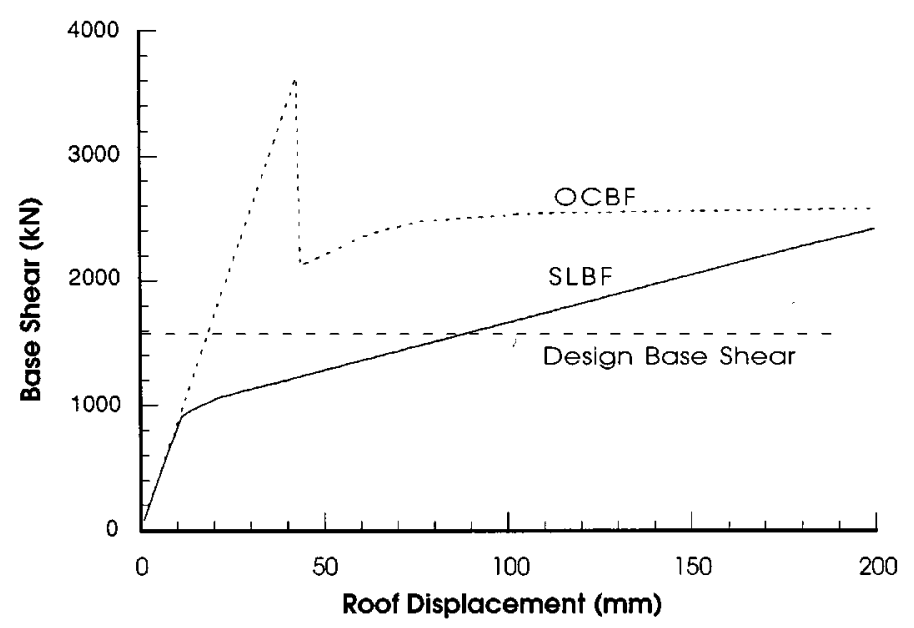

(b)

Figure 15. (a) Location of inelastic activities in the OCBF and SLBF at the collapse; and (b) plot of base-shear vs. roof displacement for the Pushover analysis

expected with only shear-links undergoing yielding. When one of the braces buckled and its load capacity dropped in the OCBF, the resulting unbalanced vertical component of brace forces overstressed the floor beam, causing plastic hinges and seriously undermining the lateral and gravity resistance of the frame. The column hinging at the base could not be avoided in either case for this design level earthquake loading. A similar failure mechanism was observed with other loadings as well; only some typical results of the analyses are presented in the following sections.

A typical comparison of the time-history response of SLBF and OCBF is shown in Figure 18, where roof displacement and base shear is plotted for the Northridge case. Note that the OCBF shows a drifting type of response which is primarily due to the formation of a mechanism in its first storey. In contrast, such problems were avoided in the SLBF due to the high stiffness and strainhardening property of the shear-links. Moreover, the low yielding SLBF system attracted less base shear than OCBF, though the reduced stiffness of a 'partially' yielded system resulted in rather large floor displacements. 


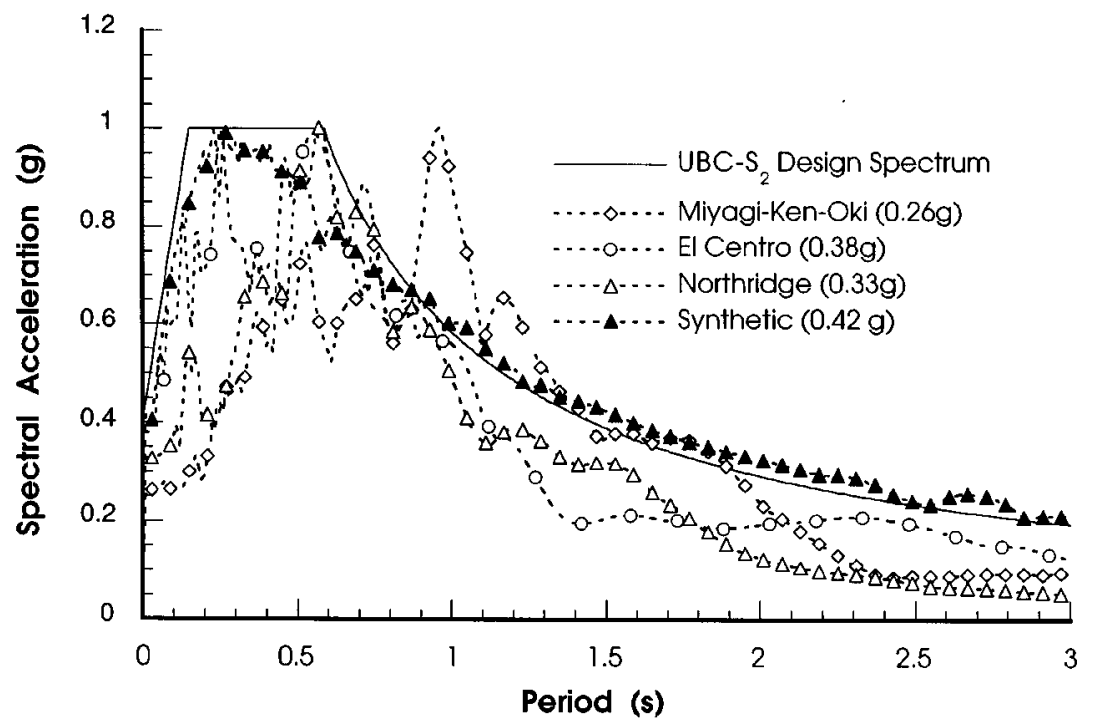

Figure 16. Comparison of the scaled ground motion spectra with the UBC $S_{2}$ design spectrum

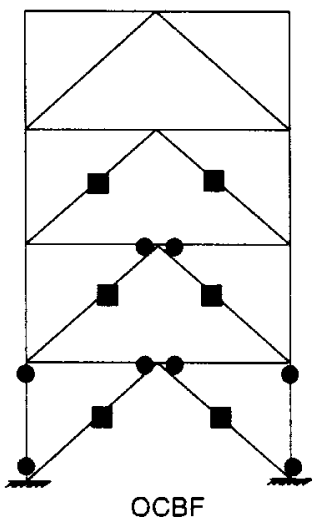

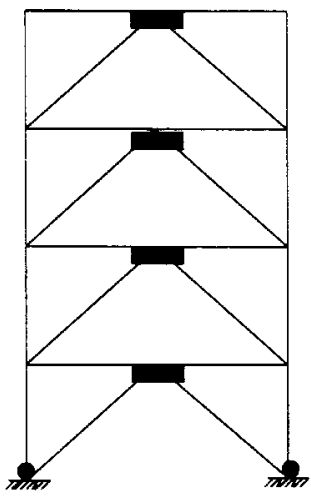

SLBF

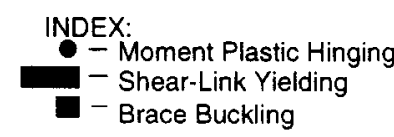

Figure 17. Location of inelastic activities at the end of $20 \mathrm{~s}$ of Miyagi-Ken-Oki earthquake record

\section{Hysteretic behaviour and energy dissipation}

The base shear vs. first-storey displacement is plotted for both frames in Figure 19 for the El Centro ground motion case. In the case of the SLBF, stable and full hysteresis loops are obtained as expected, whereas the response plot of the OCBF suffered pinched and degrading hysteretic behaviour. More energy is absorbed by the OCBF than the SLBF, but very little of this energy is dissipated by the braces of the OCBF. Most of the energy was dissipated in plastic hinges in the columns and beams in the OCBF, whereas in the SLBF, almost all of the energy was dissipated by the shear-links alone. A similar pattern in energy dissipation can be observed in Figure 20 where energy time histories for the synthetic accelerogram case is presented along with the energy absorbed in each storey for both frames.

\section{Response envelopes}

Inter-storey drift and storey shear response envelopes for both systems are compared in Figure 21 for all ground motions. Storey drift responses clearly show nearly uniform distributions of deformation for the 


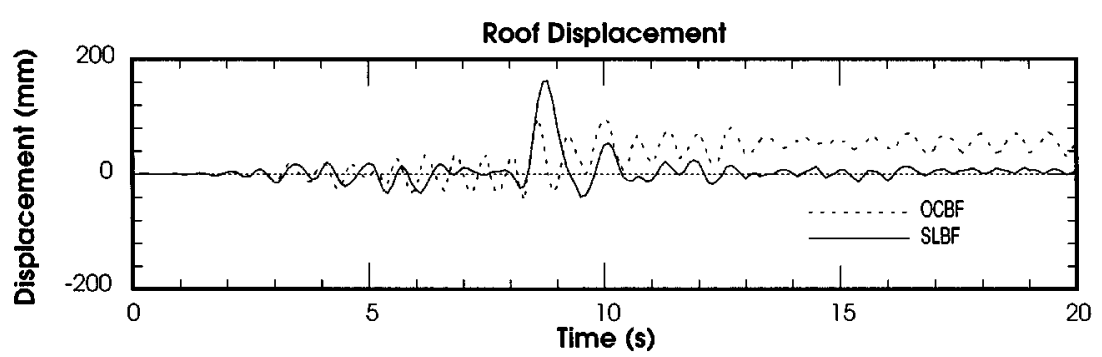

(a)

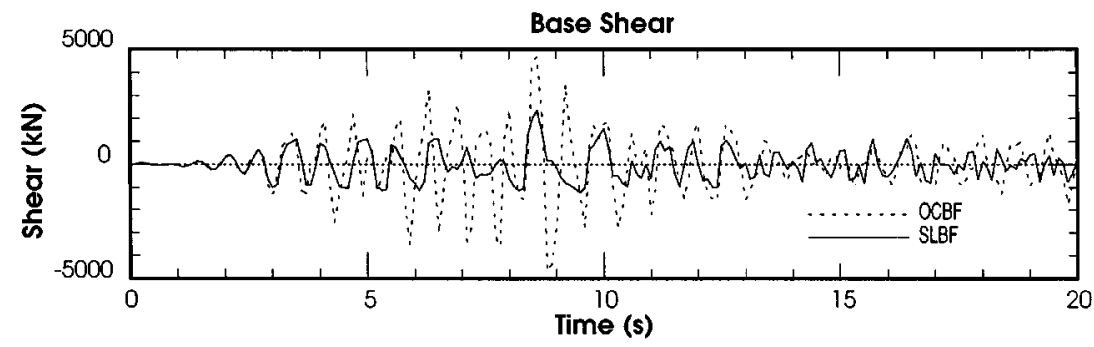

(b)

Figure 18. Comparison of time-history response of both frames (Northridge): (a) roof displacement; and (b) base shear
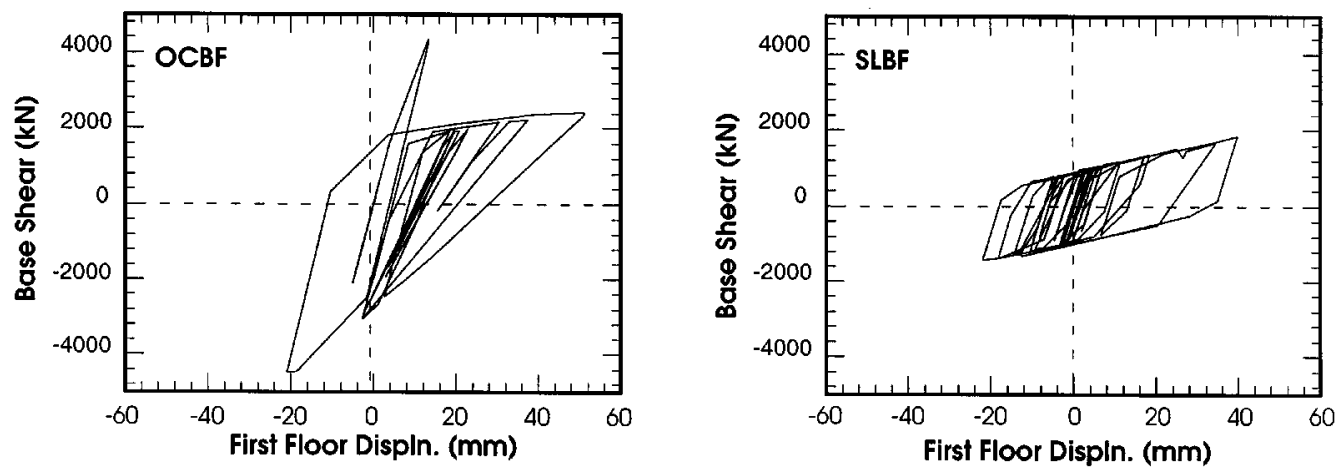

Figure 19. Hysteretic response of base shear vs. the first-storey drift in El Centro earthquake

bottom storeys of the SLBF-braced building, as opposed to the concentrated damage of OCBF-braced building at the first storey. However, only for the synthetic accelerogram case, shear-links at the third storeys were subjected to shear strain of $0.24 \mathrm{~mm} / \mathrm{mm}$, in excess of the maximum suggested value of $0 \cdot 2$. The maximum base shear resisted by the OCBF is in the range $2 \cdot 8-3 \cdot 0$ times the design base shear, while it is significantly reduced for the SLBF in the range $1 \cdot 2-1 \cdot 7$.

\section{SOME PRACTICAL CONSIDERATIONS}

\section{Galvanic (bi-metallic) corrosion}

The use of dissimilar materials (aluminium shear link in contact with steel girders and steel bolts) can cause galvanic corrosion in the presence of an electrolyte, such as moisture, in the faying surface. As a result, 

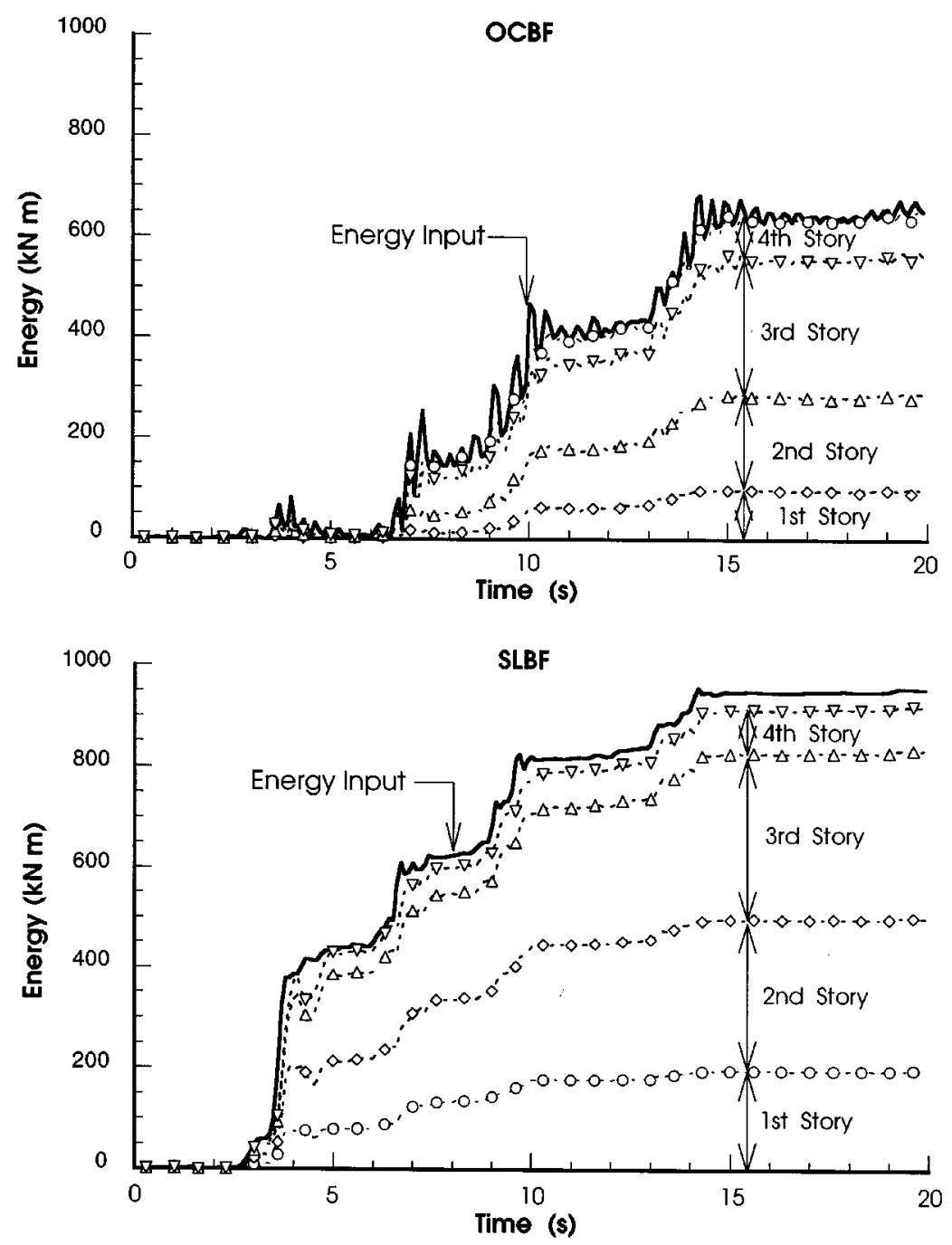

Figure 20. Comparison of energy time histories for both frames for the synthetic accelerogram case

aluminium parts may act as an anode and become eroded in time. The attack can be thwarted by isolating the two materials from each other, thus preventing the formation of the 'corrosion battery' and/or minimizing its effectiveness. Some of the practical solutions are: ${ }^{12,13}$

1. Coating the steel contact surface with a protective layer that will either break the metallic circuit which connects anode to cathode by electrically insulating one with the other, or by reversing the direction of the current in the 'battery' to protect the aluminium shear-link. Many different coating materials of organic, metallic, and composite types can be chosen. Priming and painting with zinc-rich paints is a popular choice in steel structural work and is an effective barrier against the corrosion. The use of spacers made from tough and inert materials, such as Teflon, to physically separate the electrodes can also be considered.

2. Keeping the electrolyte out of the joint by sealing it with a polysulphide, silicone, or butyl sealant to eliminate the formation of battery. 

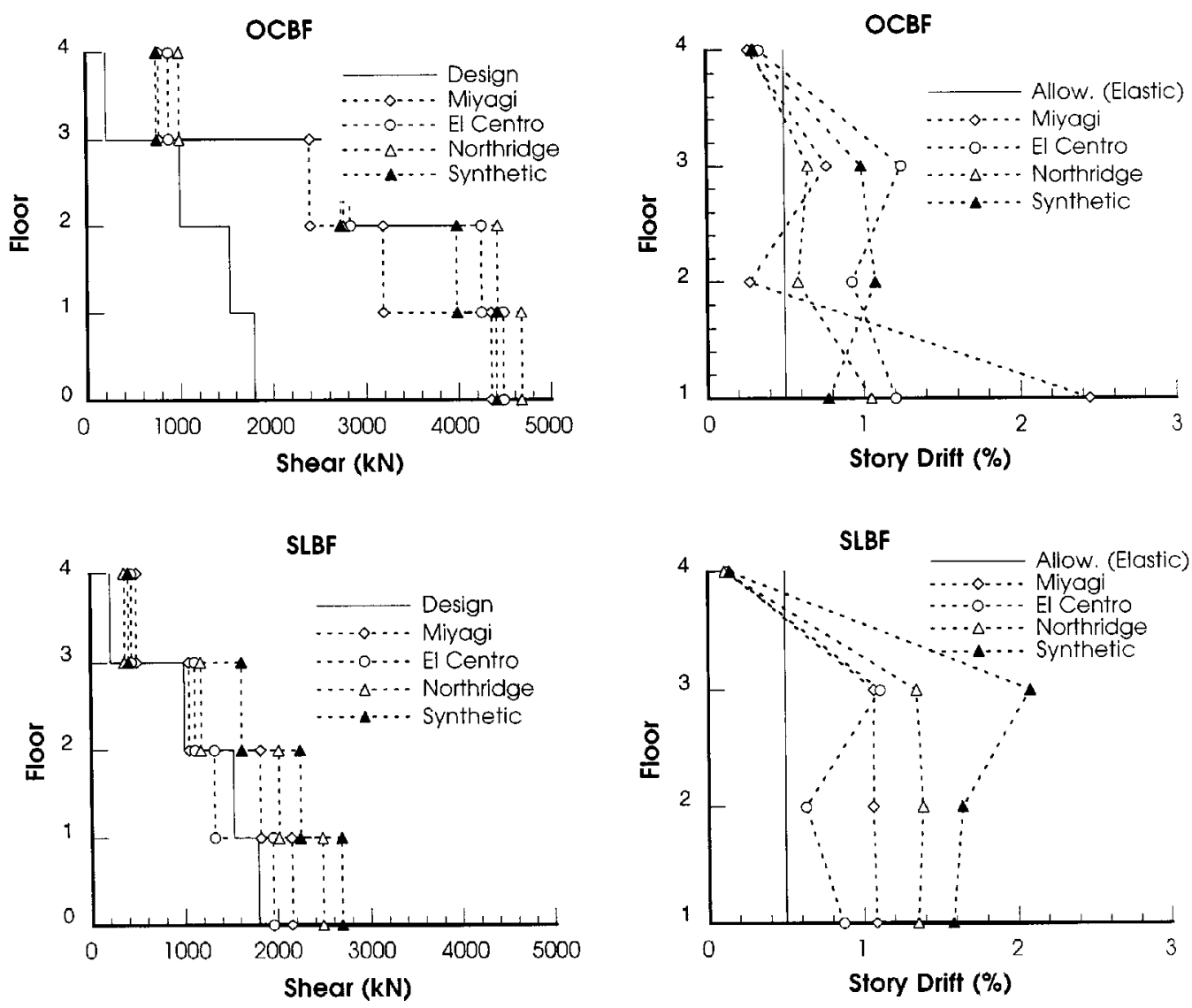

Figure 21. Response envelopes: storey drifts and storey shears

3. Using electroplated or galvanized carbon steel bolts A307 and A325 to reduce any further possibility of corrosion. Austenitic stainless-steel (200 and 300 series) fasteners can be used in its place, though they are expensive.

\section{Friction grip bolted joints}

Friction (slip-critical) connections are somewhat difficult to realize with smoother aluminium surfaces, which have a low coefficient of friction on the order of $0 \cdot 10-0 \cdot 15$. However, extensive testing has shown that if the faying surfaces are lightly shot blasted, the characteristic slip factor can be increased to $0 \cdot 30$, for a $12 \mathrm{~mm}$ thick joint, to $0 \cdot 45$, for joint thicknesses exceeding $30 \mathrm{~mm} .{ }^{14}$ The steel surface can also be roughened to further enhance the interfacial shear resistance.

Effective friction bolting involves a high pre-load stress provided by the high strength bolts, resulting in very high bearing stresses under the nut and the bolt head, which are likely to cause surface damage and local indentation. This damage causes difficulty in attaining a stable bolt pre-load and results in bolt relaxation and joint slippage as observed in specimen 2 . The damage can be eliminated by using thick steel 'washers' (as done for subsequent specimens in this study) or using steel outer plates in the butt joint, as their resistance to local stresses is greater than that of aluminium. Cullimore and Millward ${ }^{15}$ have discussed these solutions in detail in relation to the development of a compact high-performance joint using aluminium and steel plates. 
Differential thermal expansion of the aluminium and bolt steel will induce changes in the bolt force $\Theta$. For per unit change in temperature,

$$
\Theta=t_{\mathrm{a}}\left(\theta_{\mathrm{a}}-\theta_{\mathrm{s}}\right) /\left(f_{\mathrm{t}}+f_{\mathrm{p}}\right)
$$

where $\theta_{\mathrm{a}}$ and $\theta_{\mathrm{s}}$ are linear thermal expansion coefficients of aluminium and steel $\left(24 \times 10^{-6}\right.$ and $12 \times 10^{-60}$ $\mathrm{C}^{-1}$, respectively); $f_{\mathrm{t}}$ and $f_{\mathrm{p}}$ are, respectively, axial flexibilities of the bolt and plate assembly, and $t_{\mathrm{a}}$ is the thickness of aluminium plates in that assembly.

\section{CONCLUSIONS}

Aluminium shear-link demonstrated excellent stiffness and energy dissipative capacity over a wide range of strains. Though no large differences were observed between the two different alloys 3003 and 6061, the softer alloy 3003 is preferred because of its better energy dissipation characteristic. All links exhibited excellent strain hardening behaviour, which is desirable in avoiding the soft storey problem. Transverse stiffeners which restrain the pinching of hysteresis loops and delay the onset of plastic web buckling, must be provided at least at the ends of the shear-links. The overall behaviour of links was affected very little by strain rates. However, specimens tested at high strain rates were more visibly distressed than their counterparts tested quasi-statically.

The aluminium shear-links proved to be very effective and reliable in dissipating large amounts of energy. A methodology to design the proposed shear-link bracing configuration has been developed together with analytical studies which establish its suitability under earthquake-type loads. Results of the monotonic loading show the SLBF system to have high initial stiffness, with increasing strength at larger drifts. In general, dynamic response to various earthquake records resulted in lower values for the SLBF. In addition to these advantages, the SLBF-equipped structure had a reduced base shear, a more uniform distribution of storey drifts and a larger energy dissipation capacity per unit drift. Other advantages of SLBFs include easy link replacement after an extreme earthquake and the ease of tailoring different link strengths to particular storeys by adjusting link lengths. These advantages indicate that additional experimental and analytical studies of SLBFs are warranted.

\section{ACKNOWLEDGEMENTS}

Financial support from the University of Oklahoma Research Council for the material and instrumentation is gratefully acknowledged. The authors greatly appreciated the quality work of Mr. Mike Schmitz in constructing the test apparatus, manufacturing the specimens, and assembling the instrumentation and test equipment.

\section{REFERENCES}

1. D. C. Rai, 'Novel bracing system for earthquake resistance', Thesis, presented to University of Oklahoma, Norman, Oklahoma, in partial fulfillment of the requirements for the degree of Master of Science, 1992.

2. Uniform Building Code, Int. Conf. of Building Officials, Whittier, CA, 1994.

3. J. Firmansjah, S. C. Goel and D. C. Rai, 'SNAP-2D: a general purpose computer program for nonlinear structural analysis', UMCEE Report No. 96-20, Univ. of Michigan, Ann Arbor, MI, August 1996.

4. R. D. Hanson, I. D. Aiken, D. K. Nims, P. J. Richter and R. E. Bachman, 'State-of-the-art and state-of-the-practice in seismic energy dissipation', Technical Papers on Passive Energy Dissipation, ATC-17-1, ATC, March 1993, pp. 449-471.

5. A. S. Whitaker, V. V. Bertero, C. L. Thompson and L. J. Alonso, 'Seismic testing of steel plate energy dissipation devices', Earthquake Spectra 7(4), 563-604 (1991).

6. P. Rajendran, 'Small scale modeling of steel structures', Thesis, presented to University of Oklahoma, Norman, Oklahoma, in partial fulfillment of the requirements for the degree of Master of Science, 1990.

7. AISC-LRFD, Manual of Steel Construction-Load and Resistance Factor Design, American Institute of Steel Construction, Chicago, 1986.

8. K. Kasai, and E. P. Popov, 'Cyclic web buckling control for shear link beams', J. Struct. Div. ASCE 112(3), 505-523 (1986). 
9. G. Gerard, 'Critical shear stress of plates above the proportional limit', J. Appl. Mech. 15(1), 7-12 (1948).

10. T. V. Galambos (ed.), Guide to Stability Design Criteria for Metal Structures, 4th edn (SSRC), Wiley, New York, 1988 , pp. 105-108.

11. F. M. Mazzolani, Aluminum Alloy Structures, Pitman Publishing, Marshfield, MA, 1985, pp. 419-424.

12. L. M. Sharp, Behavior and Design of Aluminum Structures, McGraw-Hill, Inc., New York, 1992, pp. 271-272.

13. J. H. Bickford, An Introduction to the Design and Behavior of Bolted Joints, Marcel Dekker, Inc., New York, 1990 , pp. $549-587$.

14. J. L. Ramirez, 'Aluminium structural connections: conventional slip factors in friction grip joints', in R. Narayanan (ed.) Aluminium Structures: Advances, Design and Construction, Elsevier Applied Science, London, 1987, pp. 115-125.

15. M. S. G. Cullimore and C. P. Millward, 'Special features in the design of steel/aluminium HSFG bolted joints', Proc. Int. Conf. Budva, Yugoslavia, Civil Eng. Faculty, Belgrade University, Belgrade, 1986, pp. 317-326. 